\title{
ТЕРМИЧЕСКОЕ ОКСИДИРОВАНИЕ КАК СПОСОБ СОЗДАНИЯ НАНОРАЗМЕРНЫХ ФУНКЦИОНАЛЬНЫХ ПЛЕНОК НА ПОЛУПРОВОДНИКАХ А ВОЗДЕЙСТВИЕ ОКСИДОВ МЕТАЛЛОВ ОБЗОР
}

\author{
(C) 2018 Е. В. Томина, И. Я. Миттова, Б. В. Сладкопевцев, В. Ф. Кострюков, А. А. Самсонов, \\ Н. Н. Третьяков \\ Воронежский государственный университет, Университетская пл., 1, 394018 Воронеж, Россия \\ e-mail: tomina-e-v@yandex.ru
}

Поступила в редакцию 04.05.2018

\begin{abstract}
Аннотация. Рассмотрены особенности хемостимулирующего воздействия оксидов металлов на процесс термооксидирования полупроводников $\mathrm{A}^{\mathrm{III}} \mathrm{B}^{\mathrm{V}}$. Установлено, что химическая природа оксида-хемостимулятора и способ его введения в систему (из газовой фазы или нанесение на поверхность полупроводника) определяют механизм процесса. Оксиды $p$-металлов (PbO, $\mathrm{Sb}_{2} \mathrm{O}_{3}, \mathrm{Bi}_{2} \mathrm{O}_{3}$ ) реализуют транзитный механизм оксидирования независимо от способа их введения в систему. Оксиды $d$-металлов $\left(\mathrm{MnO}_{2}, \mathrm{~V}_{2} \mathrm{O}_{5}, \mathrm{CrO}_{3}\right)$, вводимые через газовую фазу, выступают в роли хемостимуляторов-транзиторов. Воздействие наноразмерных слоев $\mathrm{NiO}$ и $\mathrm{Co}_{3} \mathrm{O}_{4}$ развивается по транзитному типу. Для нанесённых на поверхность полупроводника наноразмерных слоёв $\mathrm{V}_{2} \mathrm{O}_{5}$ механизм их воздействия на процесс оксидирования $\mathrm{A}^{\mathrm{III}} \mathrm{B}^{\mathrm{V}}$ в значительной мере определяется методом нанесения (в рамках одного способа) - мягким или жёстким.
\end{abstract}

Ключевые слова: фосфид индия, арсенид галлия, термооксидирование, хемостимулятор, наноразмерные плёнки.

DOI: https://doi.org/10.17308/kcmf.2018.20/522

\section{I. ВВЕДЕНИЕ}

Хемостимулированное термооксидирование полупроводников $\mathrm{A}^{\mathrm{II}} \mathrm{B}^{\mathrm{V}}$ за счет изменения механизма процесса с собственного на транзитный либо каталитический позволяет блокировать отрицательный канал связи между реакциями окисления компонентов $\mathrm{A}^{\mathrm{III}}$ и $\mathrm{B}^{\mathrm{V}}$ при собственном термическом оксидировании $\mathrm{A}^{\mathrm{II}} \mathrm{B}^{\mathrm{V}}$, добиться ускоренного формирования пленок в сравнении с собственным оксидированием, в том числе и за счет разветвления процесса посредством продуктов превращения хемостимулятора, значительно снизить рабочие параметры процесса и предотвратить деградацию пленок, целенаправленно изменять состав пленок $[1,2]$.

В [3] было рассмотрено хемостимулирующее воздействие нанесённых слоёв $d$-металлов в процессах термооксидирования GaAs и InP. Оксиды являются тем классом хемостимуляторов, которые могут быть введены в систему через газовую фазу и могут быть нанесены в виде наноразмерных слоев на поверхность полупроводниковой подложки. Для хемостимулятора, по своей физико-химической природе способного взаимодействовать с полупроводником как по транзитному, так и по каталитическому типу [4-7], способ его введения в систему во многом задает реализацию того или иного механизма термооксидирования [8].

Введение оксидов из газовой фазы, когда в потоке кислорода только малое количество хемостимулятора достигает поверхности оксидируемого полупроводника, позволяет осуществлять прецизионное легирование синтезируемых образцов и формировать пленки, обладающие газочувствительными свойствами [9].

В рамках одного способа - нанесение оксидного хемостимулятора на поверхность полупроводника - можно выделить две группы методов: 
жёсткие (ЖМ), высокоэнергетические, оказывающие влияние на поверхность полупроводника ещё до начала процесса оксидирования (магнетронное распыление, электровзрыв проводника и т. д. [1013]), и мягкие (MM, низкотемпературные MO CVD, золь-гель процессы и т. д. [14-17]), почти не изменяющие поверхность полупроводника [1].

При нанесении наноразмерных слоев оксидовхемостимуляторов на полупроводниковую подложку образуется интерфейс, на котором уже в самый начальный момент времени в связанном состоянии присутствует кислород. В данном случае реакционный центр переходного состояния содержит кислород с самого начала процесса оксидирования. Это обеспечивает ускоренное окисление компонентов $\mathrm{A}^{\mathrm{III}}$ и $\mathrm{B}^{\mathrm{V}}$ по сравнению с собственным оксидированием полупроводников, поскольку уже сразу реализуется возможность передачи кислорода компонентам полупроводника при одновременной кинетической блокировке отрицательного канала связи [18]. При этом магнетронный метод нанесения позволяет формировать активную границу раздела, с повышенной химической активностью компонентов интерфейса [19]. Синтез гетероструктур с наноразмерными слоями оксидовхемостимуляторов обеспечивает создание поверхностных комплексов, задающих скорость роста, наноструктуру и свойства термических оксидных пленок уже в процессе их зарождения, до стадии регулярного роста.

Мягкие методы нанесения слоёв $\mathrm{V}_{2} \mathrm{O}_{5}$ характеризуются отсутствием высокотемпературного воздействия: осаждение геля или золя на поверхность полупроводника происходит при комнатной, а в некоторых случаях и при пониженной температуре $[20,21]$. Затем при относительно невысоких температурах (при которых не происходит оксидирование подложки) проводится отжиг с целью удаления химически связанной воды и перекристаллизации плёнок. Термооксидирование сформированных гетероструктур протекает по транзитному механизму [22]. Преимуществами мягких методов нанесения в данном случае является относительная простота реализации, варьируемый в широких пределах состав слоёв и формирование гладких плёнок с низкими значениями шероховатости.

Использование двух полупроводников типа $\mathrm{A}^{\mathrm{III}} \mathrm{B}^{\mathrm{V}}$ - GaAs и InP - со значительно различающимся «химизмом» компонентов $\mathrm{B}^{\mathrm{V}}$ и разной направленностью отрицательного канала связи между реакциями покомпонентного окисления выявляет воздействие природы полупроводниковой подлож- ки на процессы формирования, состав, структуру и свойства пленок. Более выраженная металличность индия, чем галлия, и большая неметалличность фосфора в сравнении с мышьяком [23] изначально предполагают ярко выраженную склонность их оксидов к солеобразованию в результате кислотно-основных взаимодействий, что позволяет четко проследить роль вторичных превращений в процессах формирования пленок.

\section{II. ХЕМОСТИМУЛИРУЮЩЕЕ ДЕЙСТВИЕ ОКСИДОВ $p$-МЕТАЛЛОВ В ПРОЦЕССАХ TЕРМООКСИДИРОВАНИЯ GaAs и InP}

Оксиды $p$-элементов, такие как $\mathrm{PbO}, \mathrm{Sb}_{2} \mathrm{O}_{3}$, $\mathrm{Bi}_{2} \mathrm{O}_{3}$, выступают эффективными хемостимуляторами термооксидирования $\mathrm{A}^{\mathrm{III}} \mathrm{B}^{\mathrm{V}}$ (табл. 1) как при введении их через газовую фазу [24-26], так и при нанесении на поверхность полупроводниковой подложки [27-29].

В [30] была экспериментально подтверждена транзитная передача кислорода оксидом свинца компонентам полупроводника GaAs при термическом отжиге гетероструктур $\mathrm{PbO} / \mathrm{GaAs}$ в аргоне, когда оксидная пленка на GaAs формируется в условиях отсутствия кислорода, кроме входящего в состав хемостимулятора $\mathrm{PbO}$.

На примере процесса термического оксидирования InP при введении $\mathrm{Sb}_{2} \mathrm{O}_{3}$ в газовую фазу [26] впервые было достигнуто не только значительное ускорение процесса (табл. 1; рассчитывается как отношение прироста толщины плёнки при хемостимулированном термооксидировании полупроводника к приросту толщины плёнки при собственном термооксидировании), но и снижение содержания в пленках недоокисленного индия, а также достижение тетраэдрической координации фосфора кислородом в гораздо менее жестких условиях по сравнению с эталоном.

Для всех оксидов $p$-элементов независимо от способа введения в систему (из газовой фазы либо нанесение на поверхность) характерен транзитный механизм хемостимулирующего воздействия [1] в процессах термооксидирования арсенида галлия и фосфида индия, что и следовало ожидать из общехимических соображений (табл. 1).

Но даже для одного и того же оксида-транзитора способ введения в систему существенно влияет на особенности его хемостимулирующего воздействия [29, 31, 32]. На рис. 1 представлена кинетика термического оксидирования InP при введении $\mathrm{PbO}$ через газовую фазу в изотермических условиях. Там же приведена отвечающая данному 
Таблица 1. Характеристики процессов термооксидирования GaAs и InP под воздействием оксидовхемостимуляторов, введенных из газовой фазы и нанесенных на поверхность полупроводника (гетероструктуры)

[Table 1. Characteristics of the thermal oxidation processes of GaAs and InP under the influence of oxideschemostimulators introduced from the gas phase and deposited on the surface of a semiconductor

(heterostructures)]

\begin{tabular}{|c|c|c|c|c|}
\hline $\begin{array}{l}\text { Полупроводник } \\
\text { [Semiconductor] }\end{array}$ & $\begin{array}{l}\text { Хемостимулятор } \\
\text { [Chemostimulator] }\end{array}$ & $\begin{array}{l}\text { ЭЭА, кДж/моль } \\
\text { [EEA, kJ/mol] }\end{array}$ & $\begin{array}{c}\text { Ускорение, раз } \\
\text { [Acceleration, times] }\end{array}$ & $\begin{array}{c}\text { Диэлектрическая прочность, B/cм } \\
\text { [Dielectric strength, V/cm] }\end{array}$ \\
\hline \multicolumn{5}{|c|}{$\begin{array}{c}\text { Газовая фаза } \\
{[\text { Gas phase }]}\end{array}$} \\
\hline \multirow{5}{*}{ GaAs } & $\mathrm{GeO}_{2}$ & 110 & 3 & $(5-7) \cdot 10^{5}$ \\
\hline & $\mathrm{SnO}$ & 130 & 3 & $(5-8) \cdot 10^{5}$ \\
\hline & $\mathrm{PbO}$ & 158 & 3 & $\begin{array}{l}(30-70) \cdot 10^{5} \text { (газочувствительные } \\
\text { свойства) [gas-sensitive properties] }\end{array}$ \\
\hline & $\mathrm{Sb}_{2} \mathrm{O}_{3}$ & 199 & 26 & $\begin{array}{l}(8-20) \cdot 10^{5} \text { (газочувствительные } \\
\text { свойства) [gas-sensitive properties] }\end{array}$ \\
\hline & $\mathrm{Bi}_{2} \mathrm{O}_{3}$ & 240 & 2 & $\begin{array}{c}14 \cdot 10^{5} \text { (газочувствительные } \\
\text { свойства) [gas-sensitive properties] }\end{array}$ \\
\hline \multirow{2}{*}{$\operatorname{InP}$} & $\mathrm{Sb}_{2} \mathrm{O}_{3}$ & 133 & $13-15$ & $(2-5) \cdot 10^{5}$ \\
\hline & $\mathrm{PbO}$ & 175 & 2 & $(3-8) \cdot 10^{5}$ \\
\hline \multicolumn{5}{|c|}{$\begin{array}{l}\text { Гетероструктуры (ЖМ) } \\
\text { [Heterostructures, (HM)] }\end{array}$} \\
\hline \multirow{3}{*}{ GaAs } & $\mathrm{PbO}$ & 180 & 17 & $(1-6) \cdot 10^{5}$ \\
\hline & $\mathrm{Sb}_{2} \mathrm{O}_{4}$ & 226 & 17 & \\
\hline & $\mathrm{Bi}_{2} \mathrm{O}_{3}$ & 159 & 7 & \\
\hline \multirow{2}{*}{$\operatorname{InP}$} & $\mathrm{Sb}_{x} \mathrm{O}_{y}$ & 212 & & $(4-12) \cdot 10^{5}$ \\
\hline & $\mathrm{PbO}$ & 175 & & $(2-5) \cdot 10^{6}$ \\
\hline
\end{tabular}

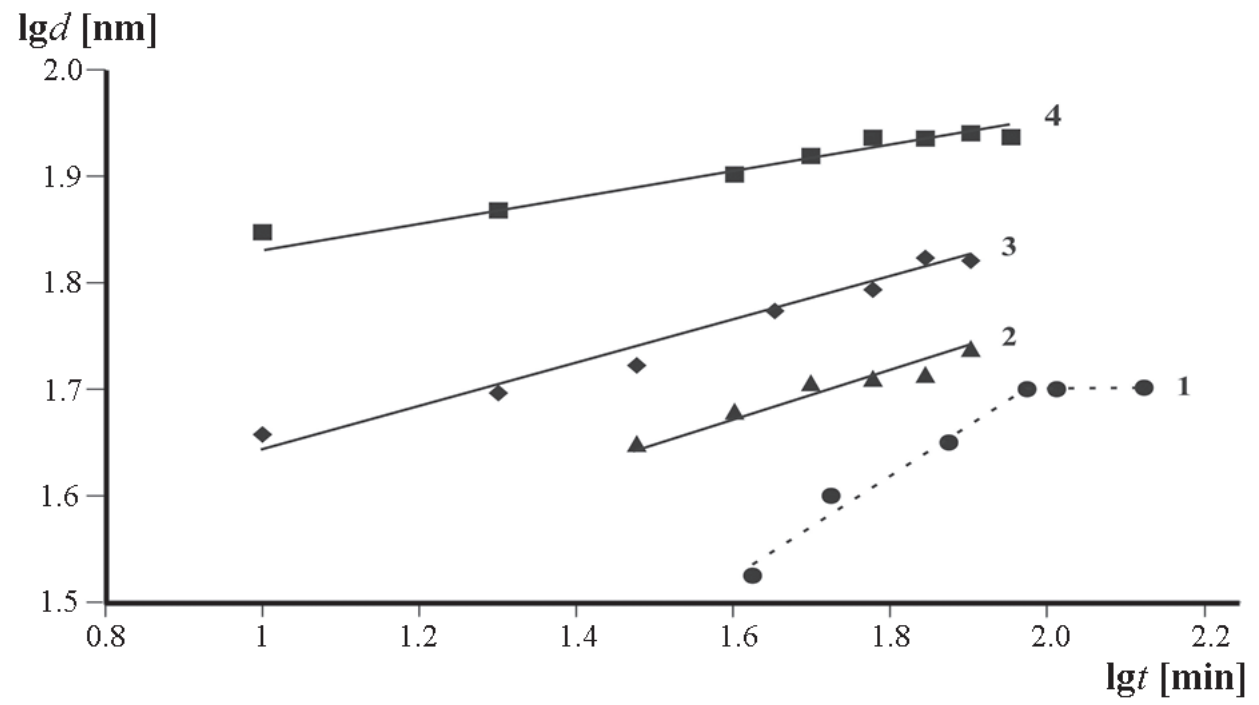

Рис. 1. Кинетические изотермы роста оксидных пленок на фосфиде индия в эталонных условиях и при введении оксида свинца в газовую фазу: 1 - эталон при 575; $2-525,3-550 ; 4-575{ }^{\circ} \mathrm{C}$

[Fig. 1. Kinetic isotherms of growth of oxide films on indium phosphide under reference conditions and when lead oxide is introduced into the gas phase: 1 - standard at $\left.575 ; 2-525 ; 3-550 ; 4-575{ }^{\circ} \mathrm{C}\right]$ 
температурно-временному интервалу изотерма эталонного оксидирования фосфида индия в отсутствие активатора [33]. Ускорение процесса формирования пленок по сравнению с собственным оксидированием полупроводника (до 2 раз, табл. 1) сопровождается значительным снижением температуры и времени оксидирования.

При этом по данным ультрамягкой рентгеновской эмиссионной спектроскопии (УМРЭС) координация фосфора кислородом до $\mathrm{PO}_{4}^{3-}$ возрастает с увеличением температуры оксидирования (рис. 2). При самой низкой температуре $525{ }^{\circ} \mathrm{C}$ соотношение максимумов А и $\mathrm{B}$, «затянутость» левого плеча максимума В на кривой 1 свидетельствуют о начале формирования тетраэдрической координации фосфора атомами кислорода, тогда как при самой высокой температуре $575{ }^{\circ} \mathrm{C}$ (кривая 3) спектр характерен для «чистого» аморфного фосфата.

Таким образом, образующиеся на начальных стадиях процесса $\mathrm{In}_{2} \mathrm{O}_{3}$ и $\mathrm{P}_{2} \mathrm{O}_{5}$ вступают во взаимодействие с образованием InPO тверждая предположение о характере определяющего процесса (фосфатообразование) и его лимитирующей стадии (взаимная диффузия оксидов).

При оксидировании InP с напыленным на поверхность слоем оксида свинца в сравнении с введением $\mathrm{PbO}$ через газовую фазу температурный интервал синтеза регулярных пленок снижается (рост оксидных пленок оказывается возможным уже при $400{ }^{\circ} \mathrm{C}$ ). При этом ЭЭА (эффективная энергия активации) составляет 152 кДж/моль, что характерно для транзитного механизма действия хемостимуляторов. По данным Оже-электронной спектроскопии (ОЭС) и инфракрасной спектроскопии (ИКС) основными компонентами пленок являются фосфаты индия и свинца [29], что способствует значительному росту элект рической прочности сформированных образцов (2-5) $10^{6} \mathrm{~B} / \mathrm{cm}$ по сравнению с вариантом введения $\mathrm{PbO}$ через газовую фазу (2$8) \cdot 10^{5} \mathrm{~B} / \mathrm{cm}$. Таким образом, при нанесении оксида $p$-элемента на поверхность полупроводника по сравнению с введением того же оксида из газовой фазы степень окисленности компонентов подложки возрастает, усиливается процесс фосфатообразования в ходе вторичных взаимодействий оксидов, улучшаются электрофизические характеристики формируемых пленок (табл. 1).

Схема механизма действия оксидов $p$-элементов с учетом протекающих транзитных взаимодействий с компонентами полупроводника на примере термооксидирования $\mathrm{GaAs}$ под влиянием вводимого через газовую фазу $\mathrm{Sb}_{2} \mathrm{O}_{3}$ представлена на рис. 3 .

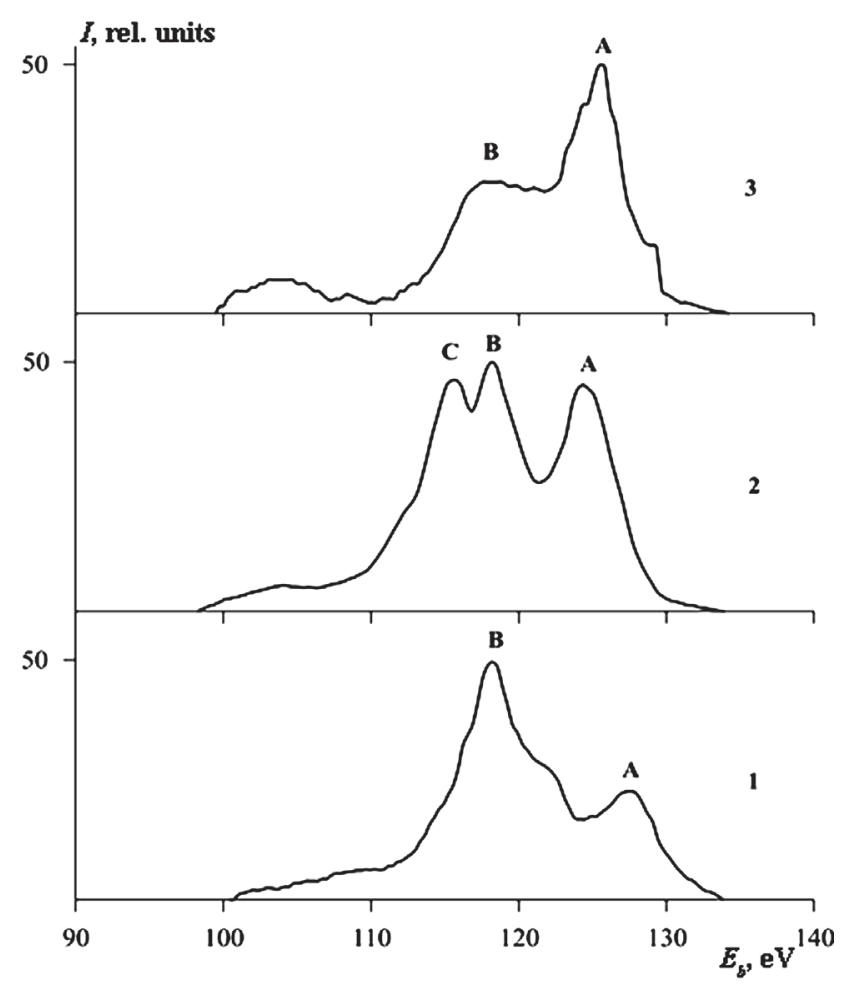

Рис. 2. Рентгеновские $\mathrm{PL}_{2,3}$-спектры образцов, сформированных термооксидированием InP в присутствии оксида свинца в газовой фазе в режимах: $1-525 \mathrm{C}$, 80 мин; $2-550{ }^{\circ} \mathrm{C}, 60$ мин; $3-575^{\circ} \mathrm{C}, 60$ мин.

[Fig. 2. X-ray $\mathrm{PL}_{2,3}$ spectra of samples formed by thermal oxidation of InP in the presence of lead oxide in the gas phase in the regimes: $1-525^{\circ} \mathrm{C}, 80 \mathrm{~min} ; 2-550{ }^{\circ} \mathrm{C}, 60 \mathrm{~min}$;

$$
\left.3-575^{\circ} \mathrm{C}, 60 \mathrm{~min} .\right]
$$

Оксид-хемостимулятор оказывает влияние на обе составляющие полупроводниковой подложки, вовлекая ее компоненты в новые, быстро протекающие химические взаимодействия (показаны в овальных рамках), которые, блокируя собственный «отрицательный» канал связи (выделен пунктиром) обеспечивают не только ускоренный рост оксидной пленки на поверхности полупроводника, но и улучшение электрофизических свойств, в частности, отсутствие омической проводимости.

\section{III. ОКСИДЫ $d$-МЕТАЛЛОВ, ВВОДИМЫЕ ИЗ ГАЗОВОЙ ФАЗЫ, КАК ХЕМОСТИМУЛЯТОРЫ ТЕРМИЧЕСКОГО ОКСИДИРОВАНИЯ GaAs И InP}

При использовании в качестве хемостимуляторов оксидов $d$-металлов вероятность разветвления процесса оксидирования за счет новых положительных каналов связи выше, нежели в случае оксидов $p$-металлов, прежде всего, за счет существования $d$-элемента в нескольких степенях окисле- 


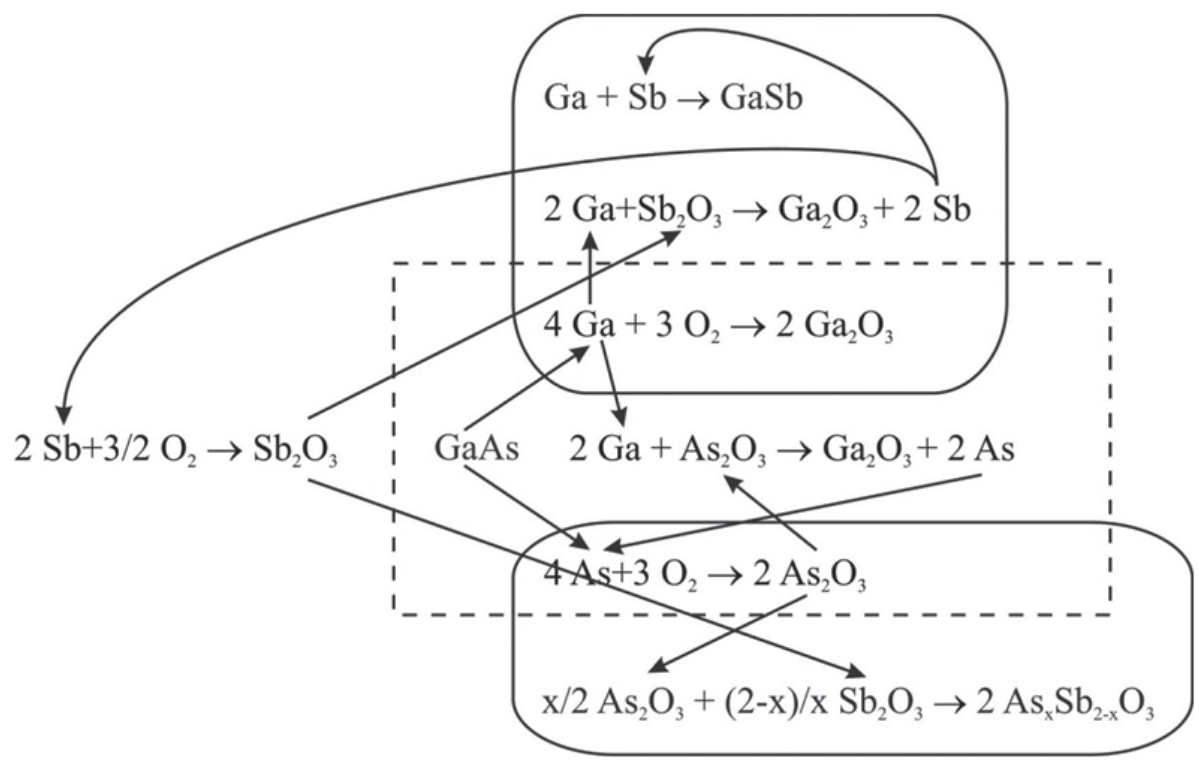

Рис. 3. Механизм процесса термического оксидирования арсенида галлия при введении $\mathrm{Sb}_{2} \mathrm{O}_{3}$ в газовую фазу [Fig. 3. Mechanism of thermal oxidation of gallium arsenide in the presence of $\mathrm{Sb}_{2} \mathrm{O}_{3}$ introduced through the gas phase]

ния в условиях эксперимента. Наличие нескольких устойчивых степеней окисления у $d$-металла является необходимым условием для реализации каталитического механизма действия оксида-хемостимулятора в процессе термического оксидирования полупроводников $\mathrm{A}^{\mathrm{III}} \mathrm{B}^{\mathrm{V}}$. Перспективными в этом плане являются оксиды марганца $\left(\mathrm{MnO}_{2}\right)$ и ванадия $\left(\mathrm{V}_{2} \mathrm{O}_{5}\right)$, то есть $d$-металлов, имеющих несколько, в равной мере устойчивых, степеней окисления. В качестве сравнения исследовано также действие оксида хрома (VI), который в высшей степени окисления является сильным окислителем, а в низшей $\left(\mathrm{Cr}_{2} \mathrm{O}_{3}\right)$, как показывают термодинамические расчеты, не способен проявлять хемостимулирующее действие. Еще одной особенностью $\mathrm{CrO}_{3}$ является то, что в условиях эксперимента он претерпевает превращения по общей схеме

$$
\mathrm{CrO}_{3} \rightarrow \mathrm{Cr}_{3} \mathrm{O}_{8} \rightarrow \mathrm{Cr}_{2} \mathrm{O}_{5} \rightarrow\left(\mathrm{CrO}_{2}\right) \rightarrow \mathrm{Cr}_{2} \mathrm{O}_{3}
$$

[34] и хемостимулирующее действие теоретически может оказывать не только сам $\mathrm{CrO}_{3}$, но и некоторые продукты его разложения.

Для объемных образцов полупроводниковых соединений $\mathrm{A}^{3} \mathrm{~B}^{5}$ известно [35-37], что легирование их марганцем приводит к сегрегации атомов примеси на дислокациях, резко снижает подвижность дислокаций в плоскостях скольжения и тем самым придает новые макроструктурные свойства материалу.

Одной из особенностей $\mathrm{V}_{2} \mathrm{O}_{5}$ является многообразие форм его существования: он может быть получен в виде тонких плёнок на разнообразных подложках [38, 39], целого ряда одномерных наноструктур (нанотрубки, нанонити, наносвитки и т. д. [40-42]). Особый интерес представляют собой гели оксида ванадия, которые являются объектом интенсивного изучения в течение последней четверти века $[43,44]$. Золь-гель синтез наноструктур на основе $\mathrm{V}_{2} \mathrm{O}_{5}$ получил широкое распространение, чему в немалой степени способствовали простота метода, мягкие условия синтеза и возможность создания различных материалов. При этом он представляется перспективной технологией для получения структур типа металл-диэлектрик-металл (МДМ) на основе гидратированного геля $\mathrm{V}_{2} \mathrm{O}_{5}[45$, 46]. Ксерогели оксида ванадия (V) имеют смешанный ионно-электронный тип проводимости, уровень составляющих которых можно изменять в широких пределах, а микроструктуру ксерогелей - варьировать в зависимости от способа последующей обработки. Основные области возможного использования таких соединений - переключающие устройства, антистатические покрытия, фотохромные и электрохромные преобразователи информации и катодные материалы в низкотемпературных источниках тока [42].

Способность ванадия в высшей степени окисления ковалентно связывать атомы кислорода, его склонность к образованию ванадил-ионов, кислотный характер $\mathrm{V}_{2} \mathrm{O}_{5}$, позволяющий ему включаться не только в катионную, но и в анионную составляющую формируемых пленок, легкость взаимного 
перехода степеней окисления +5 и +4 в оксиде за счет несимметричного расположения ионов кислорода вокруг ионов металла и рыхлости в упаковке металл-кислородных полиэдров [47] - все это определяет высокую хемостимулирующую активность $\mathrm{V}_{2} \mathrm{O}_{5}$.

Исходя из термодинамического расчета возможности транзитной передачи кислорода от оксидов марганца (II) и (IV) компоненту $\mathrm{A}^{\mathrm{III}}$ полупроводника:

$$
\begin{gathered}
\text { GaAs: } 2 \mathrm{Ga}+3 \mathrm{MnO}=\mathrm{Ga}_{2} \mathrm{O}_{3}+3 \mathrm{Mn} \\
\Delta G_{800}^{0}=-591 \text { кДж/моль } \\
2 \mathrm{Ga}+3 / 2 \mathrm{MnO}_{2}=\mathrm{Ga}_{2} \mathrm{O}_{3}+3 / 2 \mathrm{Mn} \\
\Delta G_{800}^{0}=-722 \text { кДж/моль }
\end{gathered}
$$

и рассчитанных значений давления пара над $\mathrm{MnO}$ $\left(2.710^{-4}\right.$ мм рт. ст. при $\left.1600 \mathrm{~K}\right)$ и $\mathrm{MnO}_{2}\left(2.3 \cdot 10^{-2}\right.$ мм рт. ст. при 800 К) [48, 49], видно, что $\mathrm{MnO}_{2}$ должен проявлять большую хемостимулирующую активность в процессах термооксидирования полупроводников GaAs и InP как при введении из газовой фазы, так и при нанесении на поверхность образца. Для оксида хрома рассчитать подобные характеристики невозможно из-за отсутствия в литературе необходимых данных для промежуточных оксидов хрома $\left(\mathrm{Cr}_{3} \mathrm{O}_{8}, \mathrm{Cr}_{2} \mathrm{O}_{5}\right)$.

Однако согласно [50] для рассматриваемых оксидов марганца характерны следующие переходы:

$$
\begin{aligned}
& 4 \mathrm{MnO}+\mathrm{O}_{2} \rightarrow 2 \mathrm{Mn}_{2} \mathrm{O}_{3}\left(450-550{ }^{\circ} \mathrm{C}\right) \\
& 4 \mathrm{MnO}_{2} \rightarrow 2 \mathrm{Mn}_{2} \mathrm{O}_{3}+\mathrm{O}_{2}\left(550-650^{\circ} \mathrm{C}\right)
\end{aligned}
$$

то есть Мn в первом случае повышает степень окисления $(+2 \rightarrow+3)$, а во втором случае - понижает $(+4 \rightarrow+3)$. В обоих случаях конечным продуктом является $\mathrm{Mn}_{2} \mathrm{O}_{3}$, который, видимо, и будет выступать основным хемостимулятором в процессе оксидирования GaAs, поскольку именно он присутствует в системе в наибольшем количестве, способен к транзитной передаче кислорода $\left(2 \mathrm{Ga}+\mathrm{Mn}_{2} \mathrm{O}_{3}=\mathrm{Ga}_{2} \mathrm{O}_{3}+2 \mathrm{Mn} \Delta G_{800}^{0}=-151\right.$ кДж/моль $)$ и находится в активном состоянии в момент выделения.

Значение ЭЭА для термооксидирования $\mathrm{GaAs}$ под воздействием $\mathrm{MnO}_{2}$, вводимого через газовую фазу, составляет 70 кДж/моль (табл. 2). Небольшая разница значений ЭЭА исследуемого процесса и

\begin{tabular}{|c|c|c|c|}
\hline $\begin{array}{l}\text { Оксид-хемостимулятор } \\
\text { [Oxide-chemostimulator] }\end{array}$ & $\begin{array}{c}\text { ЭЭА, кДж/моль } \\
{[\text { EEA, kJ/mol] }}\end{array}$ & $\begin{array}{l}\text { Механизм } \\
\text { [Mechanism] }\end{array}$ & $\begin{array}{c}\text { Эффективность (или достоинства, или } \\
\text { достигаемые показатели) } \\
\text { [Efficiency (or dignity, or achieved indicators)] }\end{array}$ \\
\hline \multicolumn{4}{|r|}{ (2) } \\
\hline $\mathrm{MnO}_{2}$ & 70 & $\begin{array}{l}\text { Транзитный } \\
\text { [Transit] }\end{array}$ & $\begin{array}{l}\text { Относительный прирост толщины плёнок } \\
\text { до } 2.6 \text { pa3 [the relative increase in the thick- } \\
\text { ness of films up to } 2.6 \text { times]; } \\
E=10^{5} \mathrm{~B} / \mathrm{cm}[\mathrm{V} / \mathrm{cm}]\end{array}$ \\
\hline $\mathrm{V}_{2} \mathrm{O}_{5}$ & 193 & $\begin{array}{l}\text { Транзитный } \\
\text { [Transit] }\end{array}$ & $\begin{array}{c}\text { Относительный прирост толщины плёнок } \\
\text { до } 6 \text { раз [the relative increase in the thickness } \\
\text { of films up to } 6 \text { times]; } \\
E=1.6 \times 10^{5} \mathrm{~B} / \mathrm{cm}[\mathrm{V} / \mathrm{cm}]\end{array}$ \\
\hline $\mathrm{CrO}_{3}$ & 150 & $\begin{array}{l}\text { Транзитный } \\
\text { [Transit] }\end{array}$ & $\begin{array}{c}\text { Относительный прирост толщины плёнок } \\
\text { до } 8 \text { раз [the relative increase in the thickness } \\
\text { of films up to } 8 \text { times]; } \\
E=10^{5} \mathrm{~B} / \mathrm{cm}[\mathrm{V} / \mathrm{cm}]\end{array}$ \\
\hline \multicolumn{4}{|r|}{ ( } \\
\hline $\mathrm{MnO}_{2}$ & 185 & $\begin{array}{l}\text { Транзитный } \\
\text { [Transit] }\end{array}$ & $\begin{array}{l}\text { Относительный прирост толщины плёнок } \\
\text { до } 1.4 \text { pas [the relative increase in the thick- } \\
\text { ness of films up to } 1.4 \text { times]; } \\
\qquad E=6 \times 10^{4} \mathrm{~B} / \mathrm{cm}[\mathrm{V} / \mathrm{cm}]\end{array}$ \\
\hline $\mathrm{V}_{2} \mathrm{O}_{5}$ & 164 & $\begin{array}{l}\text { Транзитный } \\
\text { [Transit] }\end{array}$ & $\begin{array}{l}\text { Относительный прирост толщины плёнок } \\
\text { до } 9 \text { раз [the relative increase in the thickness } \\
\text { of films up to } 9 \text { times]; } \\
E=10^{5} \mathrm{~B} / \mathrm{cm}[\mathrm{V} / \mathrm{cm}]\end{array}$ \\
\hline
\end{tabular}
собственного оксидирования GaAs (70 и 110 кДж

Таблица 2. Характеристики процессов термооксидирования GaAs и InP под воздействием оксидов d-металлов, вводимых через газовую фазу

[Table 2. Characteristics of the thermal oxidation processes of GaAs and InP under the influence of oxides of d-metals introduced through the gas phase] 
соответственно) указывает на транзитный характер действия хемостимулятора в рассматриваемом процессе. Значение ЭЭА для процессов оксидирования InP под воздействием $\mathrm{MnO}_{2}$, вводимого через газовую фазу, составляет 185 кДж/моль, что типично для реакции твердое-твердое без каталитического эффекта [4], и эта величина близка таковой для собственного термооксидирования InP в аналогичных режимах. Следовательно, $\mathrm{MnO}_{2}$ является транзитором в процессе термооксидирования InP, когда активная передача кислорода от $\mathrm{MnO}_{2}$ индию и фосфору приводит к значительному расходу хемостимулятора без его заметной регенерации на развитом этапе термооксидирования.

Было установлено [50, 51], что $\mathrm{V}_{2} \mathrm{O}_{5}$, введенный в газовую фазу, оказывает хемостимулирующее воздействие на термическое оксидирование GaAs и InP по транзитному механизму. Показано [50], что в этом случае для GaAs прирост толщины пленок по сравнению собственным оксидированием достигает 6 раз при значениях ЭЭА 193 и 110 кДж/моль соответственно (табл. 2). Для процесса на InP значение ускорения по толщине составляет 9 раз, ЭЭА равна 164 кДж/моль [51], в то время как для эталона 273 и 830 кДж/моль для первого и второго участков кинетических кривых соответственно, то есть никакого заметного снижения ЭЭА не обнаружено.

По данным рентгенофазового анализа (РФА) пленки, сформированные термооксидированием GaAs под воздействием $\mathrm{MnO}_{2}$, вводимого через газовую фазу, состоят из оксидов марганца $\mathrm{MnO}_{2}$, $\mathrm{Mn}_{3} \mathrm{O}_{4}, \mathrm{Mn}_{2} \mathrm{O}_{3}$ и оксидов компонентов полупроводника $\mathrm{As}_{2} \mathrm{O}_{5}$ и $\mathrm{Ga}_{2} \mathrm{O}_{3}$ (табл. 3). С ростом температуры оксидирования возрастает интенсивность рефлексов $\mathrm{Ga}_{2} \mathrm{O}_{3}$ и $\mathrm{Mn}_{2} \mathrm{O}_{3}$. Для пленок на фосфиде индия характерен аналогичный набор оксидов марганца, идентифицированы оксид и фосфат индия (содержание последнего возрастает с увеличением температуры).

Для плёнок, сформированных термооксидированием GaAs под воздействием вводимого через газовую фазу $\mathrm{V}_{2} \mathrm{O}_{5}$, методом РФА идентифицированы $\mathrm{V}_{2} \mathrm{O}_{5}, \mathrm{VO}_{2}, \mathrm{~V}_{2} \mathrm{O}_{3}, \mathrm{Ga}_{2} \mathrm{O}_{3}$ и $\mathrm{As}_{2} \mathrm{O}_{5}$ (табл. 4). С увеличением температуры процесса возрастает содержание $\mathrm{Ga}_{2} \mathrm{O}_{3}$ (рост интенсивности рефлекса $\mathrm{Ga}_{2} \mathrm{O}_{3}$ $(d=2.651 \AA)$ и появляется дополнительный пик $\left.\mathrm{Ga}_{2} \mathrm{O}_{3}(d=2.931 \AA)\right)$. Для пленок, синтезирован-

Таблица 3. Состав пленок, сформированных термооксидированием GaAs и InP под воздействием $\mathrm{MnO}_{2}$, вводимого через газовую фазу (данные РФА)

[Table 3. Composition of films formed by thermal oxidation of GaAs and InP under the influence of $\mathrm{MnO}_{2}$ introduced through the gas phase (XRD data)]

\begin{tabular}{|c|c|c|}
\hline $\begin{array}{l}\text { Режим оксидирования } \\
\text { [Oxidation conditions] }\end{array}$ & $\begin{array}{l}\text { Межплоскостное расстояние, } d_{\mathrm{hkl}} \\
{\left[\text { The interplanar spacing, } d_{\mathrm{hkl}}\right]}\end{array}$ & $\begin{array}{l}\text { Определяемая фаза } \\
\text { [Determined phase] }\end{array}$ \\
\hline \multirow{6}{*}{$\begin{array}{l}\mathrm{GaAs}, 500^{\circ} \mathrm{C}, 60 \mathrm{мин} \\
{\left[\mathrm{GaAs}, 500{ }^{\circ} \mathrm{C}, 60 \mathrm{~min}\right]}\end{array}$} & $4.244 ; 1.734$ & $\mathrm{As}_{2} \mathrm{O}_{5}$ \\
\hline & 2.651 & $\mathrm{Ga}_{2} \mathrm{O}_{3}$ \\
\hline & 2.829 & GaAs \\
\hline & $2.495 ; 2.112$ & $\mathrm{Mn}_{2} \mathrm{O}_{3}$ \\
\hline & 2.004 & $\mathrm{MnO}_{2}$ \\
\hline & 1.781 & $\mathrm{Mn}_{3} \mathrm{O}_{4}$ \\
\hline \multirow{6}{*}{$\begin{array}{l}\mathrm{GaAs}, 530^{\circ} \mathrm{C}, 60 \text { мин } \\
{\left[\mathrm{GaAs}, 530^{\circ} \mathrm{C}, 60 \mathrm{~min}\right]}\end{array}$} & $4.244 ; 1.734$ & $\mathrm{As}_{2} \mathrm{O}_{5}$ \\
\hline & 2.651 & $\mathrm{Ga}_{2} \mathrm{O}_{3}$ \\
\hline & 2.829 & GaAs \\
\hline & $2.495 ; 2.112$ & $\mathrm{Mn}_{2} \mathrm{O}_{3}$ \\
\hline & 2.004 & $\mathrm{MnO}_{2}$ \\
\hline & 1.781 & $\mathrm{Mn}_{3} \mathrm{O}_{4}$ \\
\hline \multirow{5}{*}{$\begin{array}{l}\operatorname{InP}, 500{ }^{\circ} \mathrm{C}, 60 \text { мин } \\
{\left[\operatorname{InP}, 500^{\circ} \mathrm{C}, 60 \mathrm{~min}\right]}\end{array}$} & $4.999 ; 1.729$ & $\mathrm{In}_{2} \mathrm{O}_{3}$ \\
\hline & 2.005 & $\mathrm{MnO}_{2}$ \\
\hline & $1.468 ; 2.935$ & $\mathrm{InP}$ \\
\hline & $2.494 ; 2.110$ & $\mathrm{Mn}_{2} \mathrm{O}_{3}$ \\
\hline & $1.451 ; 3.709$ & $\mathrm{InPO}_{4}$ \\
\hline \multirow{5}{*}{$\begin{array}{l}\operatorname{InP}, 530^{\circ} \mathrm{C}, 60 \text { мин } \\
{\left[\operatorname{InP}, 530^{\circ} \mathrm{C}, 60 \mathrm{~min}\right]}\end{array}$} & $4.999 ; 1.729$ & $\mathrm{In}_{2} \mathrm{O}_{3}$ \\
\hline & 2.005 & $\mathrm{MnO}_{2}$ \\
\hline & $1.468 ; 2.935$ & $\mathrm{InP}$ \\
\hline & $2.494 ; 2.110$ & $\mathrm{Mn}_{2} \mathrm{O}_{3}$ \\
\hline & $1.451 ; 3.709$ & $\mathrm{InPO}_{4}$ \\
\hline
\end{tabular}


Таблица 4. Состав пленок, сформированных термооксидированием GaAs и InP под воздействием $\mathrm{V}_{2} \mathrm{O}_{5}$, вводимого через газовую фазу

[Table 4. Composition of films formed by thermal oxidation of GaAs and InP under the influence of $\mathrm{V}_{2} \mathrm{O}_{5}$ introduced through the gas phase]

\begin{tabular}{|c|c|c|}
\hline $\begin{array}{l}\text { Полупроводник, режим оксидирования } \\
\text { [Semiconductor, oxidation conditions] }\end{array}$ & $\begin{array}{l}\text { Межплоскостное расстояние, } d_{\mathrm{hkl}} \\
\left.\text { [The interplanar spacing, } d_{\mathrm{hkl}}\right]\end{array}$ & $\begin{array}{l}\text { Определяемая фаза } \\
\text { [Determined phase] }\end{array}$ \\
\hline \multirow{6}{*}{$\begin{array}{l}\mathrm{GaAs}, 500{ }^{\circ} \mathrm{C}, 60 \mathrm{мин} \\
{\left[\mathrm{GaAs}, 500{ }^{\circ} \mathrm{C}, 60 \mathrm{~min}\right]}\end{array}$} & $4.244 ; 1.734$ & $\mathrm{As}_{2} \mathrm{O}_{5}$ \\
\hline & $3.414 ; 4.392$ & $\mathrm{~V}_{2} \mathrm{O}_{5}$ \\
\hline & 2.828 & GaAs \\
\hline & $2.480 ; 2.244$ & $\mathrm{~V}_{2} \mathrm{O}_{3}$ \\
\hline & $2.013 ; 1.921$ & $\mathrm{VO}_{2}$ \\
\hline & 2.651 & $\mathrm{Ga}_{2} \mathrm{O}_{3}$ \\
\hline \multirow{6}{*}{$\begin{array}{l}\text { GaAs, } 530{ }^{\circ} \mathrm{C}, 60 \text { мин } \\
{\left[\mathrm{GaAs}, 530{ }^{\circ} \mathrm{C}, 60 \mathrm{~min}\right]}\end{array}$} & $4.244 ; 1.734$ & $\mathrm{As}_{2} \mathrm{O}_{5}$ \\
\hline & $3.414 ; 4.392$ & $\mathrm{~V}_{2} \mathrm{O}_{5}$ \\
\hline & 2.828 & GaAs \\
\hline & $2.480 ; 2.244$ & $\mathrm{~V}_{2} \mathrm{O}_{3}$ \\
\hline & $2.013 ; 1.921$ & $\mathrm{VO}_{2}$ \\
\hline & $2.651 ; 2.931$ & $\mathrm{Ga}_{2} \mathrm{O}_{3}$ \\
\hline \multirow{7}{*}{$\begin{array}{l}\operatorname{InP}, 500^{\circ} \mathrm{C}, 60 \text { мин } \\
{\left[\operatorname{InP}, 500{ }^{\circ} \mathrm{C}, 60 \mathrm{~min}\right]}\end{array}$} & $4.999 ; 1.729$ & $\mathrm{In}_{2} \mathrm{O}_{3}$ \\
\hline & $3.414 ; 4.392$ & $\mathrm{~V}_{2} \mathrm{O}_{5}$ \\
\hline & $1.468 ; 2.935$ & InP \\
\hline & $2.480 ; 2.244$ & $\mathrm{~V}_{2} \mathrm{O}_{3}$ \\
\hline & $2.013 ; 1.921$ & $\mathrm{VO}_{2}$ \\
\hline & $1.451 ; 3.709$ & $\mathrm{InPO}_{4}$ \\
\hline & $4.648 ; 1.915$ & $\mathrm{InVO}_{4}$ \\
\hline \multirow{7}{*}{$\begin{array}{c}\operatorname{InP}, 530^{\circ} \mathrm{C}, 60 \text { мин } \\
{\left[\operatorname{InP}, 530{ }^{\circ} \mathrm{C}, 60 \mathrm{~min}\right]}\end{array}$} & $4.999 ; 1.729$ & $\mathrm{In}_{2} \mathrm{O}_{3}$ \\
\hline & $3.414 ; 4.392$ & $\mathrm{~V}_{2} \mathrm{O}_{5}$ \\
\hline & $1.468 ; 2.935$ & InP \\
\hline & $2.480 ; 2.244$ & $\mathrm{~V}_{2} \mathrm{O}_{3}$ \\
\hline & $2.013 ; 1.921$ & $\mathrm{VO}_{2}$ \\
\hline & $1.451 ; 3.709$ & $\mathrm{InPO}_{4}$ \\
\hline & $4.648 ; 1.915$ & $\mathrm{InVO}_{4}$ \\
\hline
\end{tabular}

ных оксидированием InP под воздействием $\mathrm{V}_{2} \mathrm{O}_{5}$ из газовой фазы, методом РФА помимо оксидов ванадия в разных степенях окисления и оксида индия выявлены рефлексы, отвечающие InPO, Незначительное содержание в пленках продуктов вторичных взаимодействий соотвествующих оксидов (арсенатов, фосфатов) обуславливает невысокие значения электрической прочности пленок (табл. 2).

Как было указано выше, $\mathrm{CrO}_{3}$ в процессе своего воздействия на термооксидирование GaAs претерпевает ряд превращений. При этом за время эксперимента процесс его термолиза полностью не завершается, и хемостимулирующее действие оказывают все присутствующие в системе промежуточные оксиды. При этом выделить парциальные вклады каждого оксида оказывается невоз- можным. Можно лишь фиксировать интегральное ускорение процесса в зависимости от температуры и времени.

Исходя из общехимических соображений, можно было бы ожидать, что способность к транзитной передаче кислорода должна уменьшаться с понижением степени окисления хрома в оксидах, равно как и летучесть соответствующих оксидных форм (от легкоплавкого и летучего $\mathrm{CrO}_{3}$ с молекулярной структурой до тугоплавкого $\mathrm{Cr}_{2} \mathrm{O}_{3}$, характеризующегося координационным строением, высокой термодинамической стабильностью и практически нелетучего).

Таким образом, с увеличением времени процесса интегральное хемостимулирующее действие продуктов термолиза $\mathrm{CrO}_{3}$ должно ослабевать, а с увеличением температуры этот эффект должен ста- 
новиться более заметным, поскольку возрастает скорость разложения исходного активатора.

Однако эксперимент показывает, что в « $\mathrm{CrO}_{3}$ »-процессе ускорение по толщине возрастает как с увеличением времени, так и температуры. Это и доказывает определяющий хемостимулирующий вклад промежуточных оксидных форм $\mathrm{Cr}_{3} \mathrm{O}_{8}$ и $\mathrm{Cr}_{2} \mathrm{O}_{5}$, количество которых нарастает с увеличением как времени, так и температуры процесса.

Общая совокупность процессов, протекающих при термооксидировании $\mathrm{GaAs}$ арсенида галлия под воздействием $\mathrm{CrO}_{3}$ и его производных (схема составлена на основании результатов РФА, УМРЭС, локального рентгеноспектрального микроанализа (ЛРСМА), инфракрасной спектроскопии (ИКС)), представлена на рис. 4. Из схемы видно, что подавление отрицательного канала связыва- ния осуществляется именно за счет производных хрома (данное направление показано пунктиром). С одной стороны, имеет место прямая блокировка взаимодействия галлия с оксидом мышьяка за счет вовлечения его в реакции с оксидами хрома в различных степенях окисления, а, с другой стороны, при взаимодействии самой подложки с производными $\mathrm{CrO}_{3}$ образуются ее окисленные формы $\left(\mathrm{Ga}_{2} \mathrm{O}_{3}, \mathrm{As}_{2} \mathrm{O}_{3}\right)$, что также благоприятно сказывается на электрофизических свойствах получаемых пленок.

Хемостимулированное термооксидирование GaAs и InP под воздействием оксидов $d$-металлов, вводимых через газовую фазу, позволяет формировать пленки с приемлемыми морфологическими характеристиками (рис. 5). Так для пленок, выращенных термооксидированием InP под воздейс-

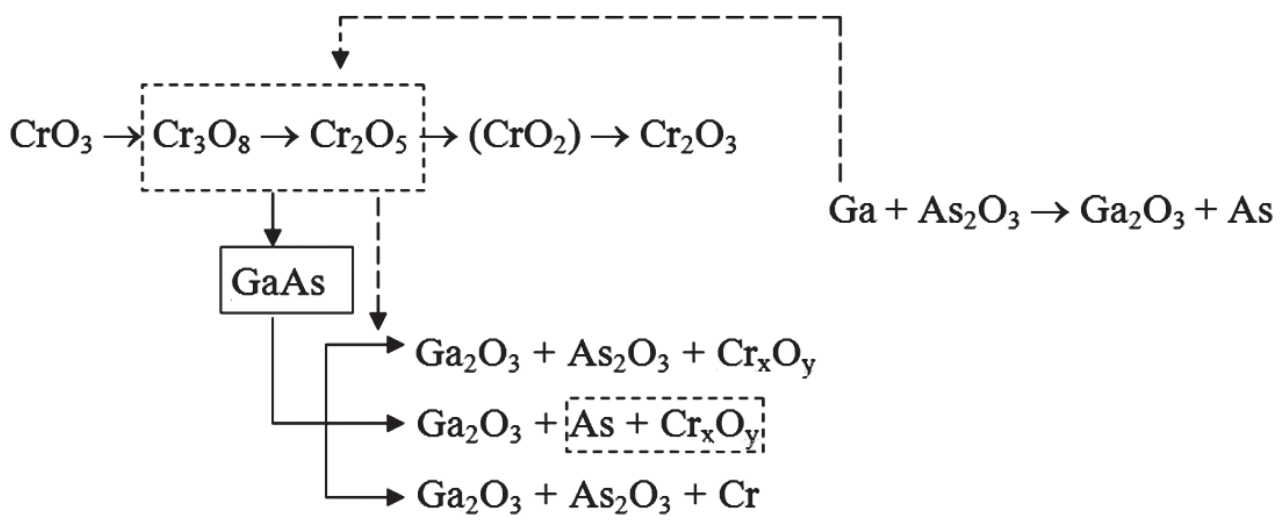

Рис. 4. Схема процесса термооксидирования $\mathrm{GaAs}$ при введении $\mathrm{CrO}_{3}$ в газовую окисляющую среду

[Fig. 4. Scheme of the process of GaAs thermal oxidation upon the $\mathrm{CrO}_{3}$ introduced through the gas phase]
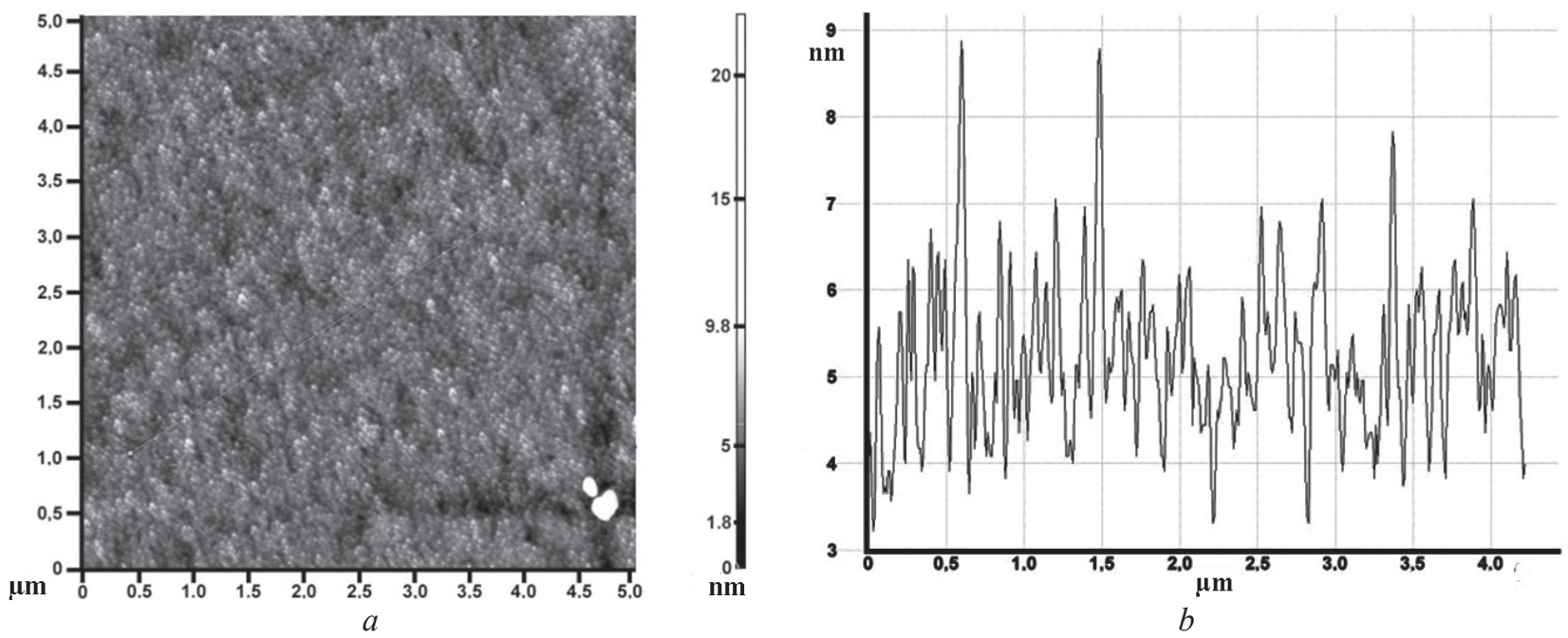

Рис. 5. АСМ-изображение поверхности ( $a$ ) и профиль поверхности $(b)$ пленки, сформированной термооксидированием InP под воздействием $\mathrm{MnO}_{2}$, вводимого через газовую фазу, в режиме $530{ }^{\circ} \mathrm{C}, 60$ мин (область сканирования $5 \times 5$ мкм $\left.^{2}\right)$

[Fig. 5. AFM image of the surface $(a)$ and the surface profile $(b)$ of the film formed by thermal oxidation of InP under the influence of $\mathrm{MnO}_{2}$ introduced through the gas phase, at $530{ }^{\circ} \mathrm{C}, 60 \mathrm{~min}$. (scanning area $\left.\left.5 \times 5 \mu \mathrm{m}^{2}\right)\right]$ 
твием $\mathrm{MnO}_{2}$, максимальный перепад высоты рельефа равен 12 нм, высота поверхности по 10 точкам составляет 14.5 нм, средняя арифметическая $S_{\text {а }}$ средняя квадратичная $S_{\mathrm{q}}$ шероховатости имеют значения равные 2 и 3 нм соответственно. Латеральный размер кристаллитов порядка 35-40 нм.

Термооксидирование InP под воздействием вводимого через газовую фазу $\mathrm{V}_{2} \mathrm{O}_{5}$ при температуре $530{ }^{\circ} \mathrm{C}$ в течение 60 минут приводит к формированию пленок с латеральным размером кристаллитов порядка 40 нм, равномерно распределенных по всей поверхности и имеющих округлую форму (рис. 6). Максимальный перепад высоты рельефа равен 45 нм, высота поверхности по 10 точкам -23 нм, $S_{\mathrm{a}}$ и $S_{\mathrm{q}}$ имеют значения равные 4.6 и 6 нм соответственно.

\section{IV. ВЛИЯНИЕ НАНЕСЕННЫХ НА ПОВЕРХНОСТЬ InP И GaAs НАНОРАЗМЕРНЫХ СЛОЕВ ОКСИДОВ $d$-МЕТАЛЛОВ НА КИНЕТИКУ И МЕХАНИЗМ ТЕРМИЧЕСКОГО ОКСИДИРОВАНИЯ ПОЛУПРОВОДНИКОВ}

Сравнительный анализ кинетических параметров процессов оксидирования гетероструктур $\mathrm{NiO}\left(\mathrm{Co}_{3} \mathrm{O}_{4}\right) / \mathrm{InP}(\mathrm{GaAs})$ (табл. 5) позволяет сделать вывод, что для всех исследуемых гетероструктур ЭЭА сравнима, а по большей части превышает ЭЭА процессов собственного оксидирования полупроводников при значениях $n_{\text {ср }}<0.5$.

При одновременном значительном увеличении относительного прироста толщины пленок по срав- нению с процессами собственного оксидирования GaAs и InP с учетом данных физико-химических методов анализа можно говорить о транзитном характере термооксидирования данных гетероструктур [52-58].

Схема механизма хемостимулирующего действия оксидов никеля и кобальта по транзитному типу на примере $\mathrm{NiO} / \mathrm{InP}$ представлена на рис. 7.

Интенсивно протекающие по транзитному типу окислительно-восстановительные взаимодействия оксидов никеля и кобальта с компонентами полупроводниковых подложек в процессах оксидирования приводят к значительно большей окисленности $\mathrm{A}^{\mathrm{III}}$ и $\mathrm{B}^{\mathrm{V}}$ по сравнению с собственным оксидированием полупроводников в тех же условиях $[33,59]$.

Фосфаты и арсенаты, являющиеся продуктами вторичного взаимодействия соответствующих оксидов, при оксидировании гетероструктур $\mathrm{NiO}\left(\mathrm{Co}_{3} \mathrm{O}_{4}\right) / \mathrm{InP}(\mathrm{GaAs})$ за счет быстрого нарастания концентрации оксидов $\mathrm{A}^{\mathrm{III}}$ и $\mathrm{B}^{\mathrm{V}}$ в ходе транзитных взаимодействий формируются в гораздо более мягких температурно-временных режимах, нежели при собственном оксидировании GaAs и InP. При этом в силу гораздо большей кислотности оксидов фосфора по сравнению с оксидами мышьяка процессы фосфатообразования выражены гораздо ярче, а спектр образующихся фосфатов намного шире (данные ИКС и РФА), тогда как арсенаты представлены в основном ортоарсенатами (табл. 6).

Практическое отсутствие стадии регенерации $\mathrm{NiO}$ и $\mathrm{Co}_{3} \mathrm{O}_{4}$ (может протекать только частичное

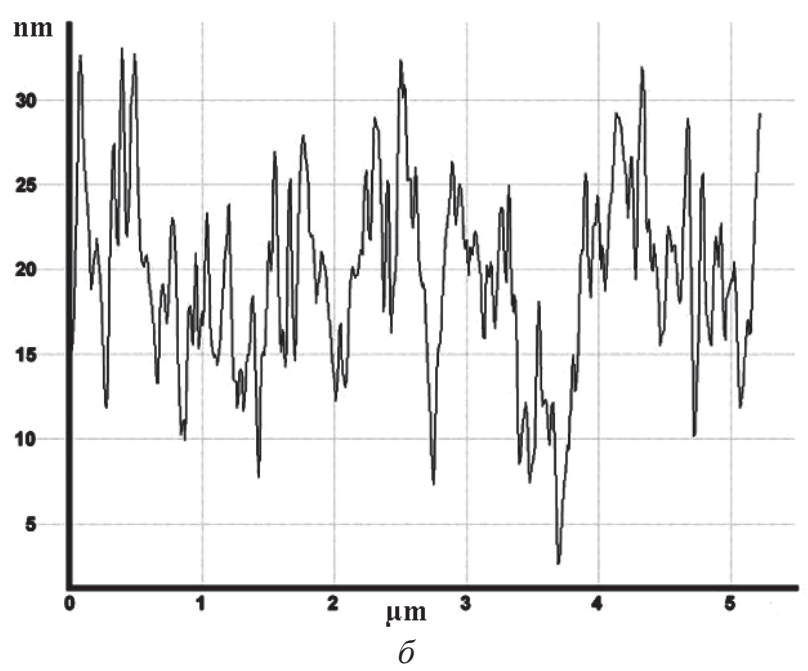

Рис. 6. АСМ-изображение поверхности $(a)$ и профиль поверхности $(b)$ пленки, сформированной термооксидированием InP под воздействием $\mathrm{V}_{2} \mathrm{O}_{5}$, вводимого через газовую фазу, в режиме $530{ }^{\circ} \mathrm{C}, 60$ мин (область сканирования $5 \times 5$ мкм $^{2}$ )

[Fig. 6. AFM image of the surface $(a)$ and the surface profile $(b)$ of the film formed by thermal oxidation of InP under the influence of $\mathrm{V}_{2} \mathrm{O}_{5}$ introduced through the gas phase, at the $530{ }^{\circ} \mathrm{C}, 60 \mathrm{~min}\left(\right.$ scanning area $\left.5 \times 5 \mu \mathrm{m}^{2}\right)$ ] 
Таблица 5. Характеристики процессов термооксидирования GaAs и InP под воздействием магнетронно нанесённых наноразмерных слоев оксидов металлов на поверхности (жёсткий метод нанесения)

[Table 5. Characteristics of the thermal oxidation processes of GaAs and InP under influence of magnetrondeposited nanoscale layers of metal oxides deposited on the surface of semiconductor (a hard method of deposition)]

\begin{tabular}{|c|c|c|c|}
\hline $\begin{array}{l}\text { Гетероструктура } \\
\text { [Heterostructure] }\end{array}$ & $\begin{array}{l}\text { ЭЭА, кДж/моль } \\
\text { [EEA, kJ/mol] }\end{array}$ & $\begin{array}{c}\text { Механизм } \\
{[\text { Mechanism }]}\end{array}$ & $\begin{array}{c}\text { Эффективность (или достоинства, или достигаемые } \\
\text { показатели) } \\
\text { [Efficiency (or dignity, or achieved indicators)] }\end{array}$ \\
\hline $\mathrm{NiO}(40$ нм $[\mathrm{nm}]) / \mathrm{GaAs}$ & 64 & $\begin{array}{l}\text { Транзитный } \\
\text { [Transit] }\end{array}$ & $\begin{array}{l}\text { Относительный прирост толщины плёнок до } 35 \% \\
\text { [the relative increase in the thickness of films up to } 35 \%] \text {; } \\
\qquad \rho=5 \times 10^{8} \mathrm{OM} \cdot \mathrm{cm}[\Omega \cdot \mathrm{cm}] \\
E=6 \times 10^{5} \mathrm{~B} / \mathrm{cm}[\mathrm{V} / \mathrm{cm}]\end{array}$ \\
\hline $\mathrm{Co}_{3} \mathrm{O}_{4}(70 \mathrm{HM}[\mathrm{nm}]) / \mathrm{GaAs}$ & 133 & $\begin{array}{l}\text { Транзитный } \\
\text { [Transit] }\end{array}$ & $\begin{array}{l}\text { Относительный прирост толщины плёнок до } 55 \% \\
\text { на начальном этапе } \\
\text { [the relative increase in the thickness of films up to } 55 \% \\
\text { at the initial stage]; } \\
\rho=9 \times 10^{8} \mathrm{OM} \cdot \mathrm{cm}[\Omega \cdot \mathrm{cm}] \\
E=8 \times 10^{5} \mathrm{~B} / \mathrm{cm}[\mathrm{V} / \mathrm{cm}]\end{array}$ \\
\hline $\mathrm{V}_{2} \mathrm{O}_{5}(25 \mathrm{HM}[\mathrm{nm}]) / \mathrm{GaAs}$ & 40 & $\begin{array}{l}\text { Каталити- } \\
\text { ческий } \\
\text { [Catalytic] }\end{array}$ & $\begin{array}{l}\text { Относительный прирост толщины плёнок до } 90 \% \\
\text { [the relative increase in the thickness of films up to } 90 \%] \text {; } \\
\qquad \begin{array}{c}\rho=7 \times 10^{8} \text { Oм.cм }[\Omega \cdot \mathrm{cm}] ; \\
E=6 \times 10^{5} \mathrm{~B} / \mathrm{cm}[\mathrm{V} / \mathrm{cm}]\end{array}\end{array}$ \\
\hline $\mathrm{NiO}(30$ нм[nm])/InP & 169 & $\begin{array}{l}\text { Транзитный } \\
\text { [Transit] }\end{array}$ & $\begin{array}{l}\text { Относительный прирост толщины плёнок до } 50 \text { \%; } \\
\text { [the relative increase in the thickness of films up to } 50 \% \text { ] }\end{array}$ \\
\hline $\mathrm{Co}_{3} \mathrm{O}_{4}(80 \mathrm{HM}[\mathrm{nm}]) / \mathrm{InP}$ & $60 / 870$ & $\begin{array}{l}\text { Транзитный } \\
\text { [Transit] }\end{array}$ & $\begin{array}{l}\text { Относительный прирост толщины плёнок до } 80 \text { \%; } \\
\text { [the relative increase in the thickness of films up to } 80 \% \text { ] }\end{array}$ \\
\hline $\mathrm{V}_{2} \mathrm{O}_{5}(25 \mathrm{HM}[\mathrm{nm}]) / \mathrm{InP}$ & 30 & $\begin{array}{l}\text { Каталити- } \\
\text { ческий } \\
\text { [Catalytic] }\end{array}$ & $\begin{array}{l}\text { Относительный прирост толщины плёнок до } 110 \% \text {; } \\
\text { [the relative increase in the thickness of films up to } 110 \%] \\
\qquad \rho=3.6 \times 10^{9} \mathrm{OM} \cdot \mathrm{cm}[\Omega \cdot \mathrm{cm}] ; \\
E=3 \times 10^{6} \mathrm{~B} / \mathrm{cm}[\mathrm{V} / \mathrm{cm}]\end{array}$ \\
\hline
\end{tabular}

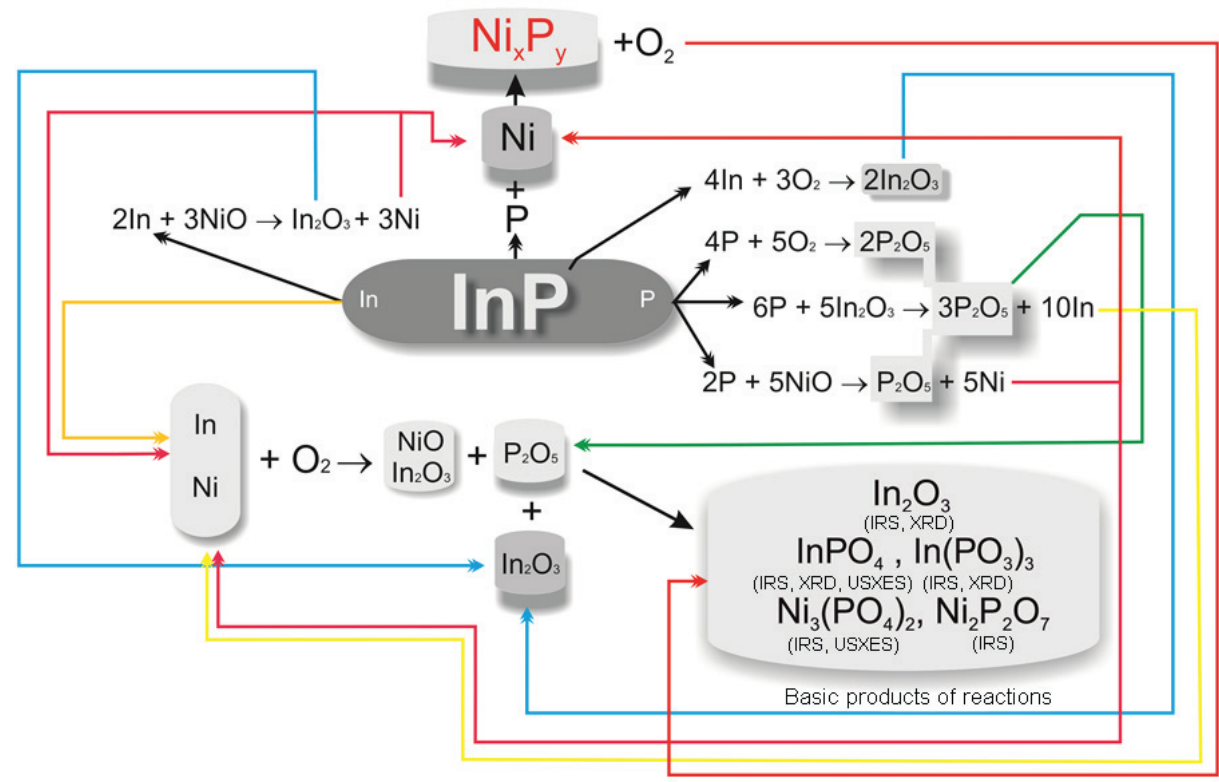

Рис. 7. Схема химических превращений при термооксидировании гетероструктуры $\mathrm{NiO} / \mathrm{InP}$

[Fig. 7. Scheme of chemical transformations during thermal oxidation of the $\mathrm{NiO} / \mathrm{InP}$ heterostructure] 
Таблица 6. Состав пленок, сформированных оксидированием гетероструктур $\mathrm{NiO}\left(\mathrm{Co}_{3} \mathrm{O}_{4}\right) / \mathrm{GaAs}(\mathrm{InP})$ (данные ИКС, РФА)

[Table 6. Composition of films formed by oxidation of $\mathrm{NiO}\left(\mathrm{Co}_{3} \mathrm{O}_{4}\right) / \mathrm{GaAs}(\mathrm{InP})$ heterostructures (IRS, XRD data)]

\begin{tabular}{|c|c|c|c|}
\hline \multirow{2}{*}{$\begin{array}{l}\text { Гетероструктура } \\
\text { [Heterostructure] }\end{array}$} & \multicolumn{2}{|c|}{$\begin{array}{l}\text { Режим оксидирования } \\
\text { [Oxidation condition] }\end{array}$} & \multirow{2}{*}{$\begin{array}{l}\text { Идентифицированные соединения } \\
\text { [Identified compounds] }\end{array}$} \\
\hline & $T,{ }^{\circ} \mathrm{C}$ & $\begin{array}{c}\tau, \text { мин } \\
{[\tau, \mathrm{min}]}\end{array}$ & \\
\hline \multirow{3}{*}{$\mathrm{NiO}(25 \mathrm{нм}[\mathrm{nm}]) / \mathrm{GaAs}$} & 450 & 10 & $\mathrm{Ga}_{2} \mathrm{O}_{3} \mathrm{As}_{2} \mathrm{O}_{3} \mathrm{NiAs}$ \\
\hline & 450 & 100 & $\mathrm{Ga}_{2} \mathrm{O}_{3} \mathrm{As}_{2} \mathrm{O}_{3} \mathrm{Ni}_{3}\left(\mathrm{AsO}_{4}\right)_{2} \mathrm{Ni}_{2} \mathrm{As}_{2} \mathrm{O}_{7}$ \\
\hline & 540 & 100 & $\mathrm{Ga}_{2} \mathrm{O}_{3} \mathrm{As}_{2} \mathrm{O}_{3} \mathrm{Ni}_{3}\left(\mathrm{AsO}_{4}\right)_{2} \mathrm{NiAs}_{2} \mathrm{O}_{4}$ \\
\hline \multirow[b]{2}{*}{$\mathrm{Co}_{3} \mathrm{O}_{4}(25 \mathrm{Hм}[\mathrm{nm}]) / \mathrm{GaAs}$} & 470 & 40 & $\mathrm{Ga}_{2} \mathrm{O}_{3} \mathrm{As}_{2} \mathrm{O}_{3} \mathrm{CoO}, \mathrm{Co}_{3} \mathrm{O}_{4}$ \\
\hline & 510 & 100 & $\begin{array}{c}\mathrm{Ga}_{2} \mathrm{O}_{3}, \mathrm{As}_{2} \mathrm{O}_{3}, \mathrm{CoO}, \mathrm{Co}_{3} \mathrm{O}_{4} \\
\mathrm{Co}_{3}\left(\mathrm{AsO}_{4}\right)_{2}\end{array}$ \\
\hline \multirow{2}{*}{$\mathrm{NiO}(30$ нм[nm])/InP } & 530 & 30 & $\mathrm{In}_{2} \mathrm{O}_{3} \mathrm{InPO}_{4} \mathrm{In}\left(\mathrm{PO}_{3}\right)_{3} \mathrm{NiO}, \mathrm{Ni}_{3}\left(\mathrm{PO}_{4}\right)_{2}$ \\
\hline & 530 & 90 & $\mathrm{In}_{2} \mathrm{O}_{3} \operatorname{InPO} \mathrm{PO}_{4} \mathrm{In}\left(\mathrm{PO}_{3}\right)_{3} \mathrm{Ni}_{3}\left(\mathrm{PO}_{4}\right)_{2} \mathrm{Ni}_{2} \mathrm{P}_{2} \mathrm{O}_{7}$ \\
\hline \multirow{2}{*}{$\mathrm{Co}_{3} \mathrm{O}_{4}(80 \mathrm{Hм}[\mathrm{nm}]) / \mathrm{InP}$} & 480 & 100 & $\begin{array}{c}\mathrm{In}_{2} \mathrm{O}_{3,}, \mathrm{InPO}_{4} \mathrm{In}\left(\mathrm{PO}_{3}\right)_{3}, \mathrm{Co}_{3} \mathrm{O}_{4}, \mathrm{Co}_{3}\left(\mathrm{PO}_{4}\right)_{2} \\
\mathrm{Co}_{2} \mathrm{P}_{2} \mathrm{O}_{7} \mathrm{Co}_{2} \mathrm{P}_{4} \mathrm{O}_{12}\end{array}$ \\
\hline & 510 & 100 & 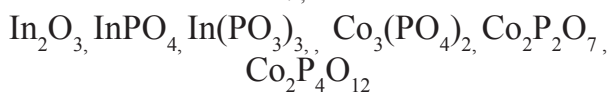 \\
\hline
\end{tabular}

окисление металла за счет взаимодействия с продиффундировавшим кислородом) приводит к расходованию оксидов-транзиторов с развитием процесса оксидирования во времени за счет осуществления транзита и некоторой диффузии металла в полупроводниковую подложку. Толщина слоя напыленного оксида в данном случае определяет момент полного расходования хемостимулятора.

Для нанесённого жёстким методом магнетронного распыления оксида ванадия установлено наибольшее хемостимулирующее действие в процессах оксидирования InP и $\mathrm{GaAs}$, заключающееся в окислительно-восстановительном взаимодействии $\mathrm{V}_{2} \mathrm{O}_{5}$ с компонентами подложки по каталитическому типу. Резкое снижение ЭЭА термооксидирования гетероструктур $\mathrm{V}_{2} \mathrm{O}_{5} / \mathrm{InP}(\mathrm{GaAs})$ (более чем в 6 раз) при большом приросте толщины пленок по сравнению с собственным оксидированием полупроводников (90 \% для GaAs и $110 \%$ для InP) однозначно указывает на то, что процесс взаимодействия хемостимулятора с компонентами полупроводника не носит транзитный характер, а, вероятнее всего, является синхронно-каталитическим.

При оксидировании гетероструктур $\mathrm{V}_{2} \mathrm{O}_{5}$ / InP с толщиной магнетронно нанесенного слоя $\mathrm{V}_{2} \mathrm{O}_{5}$ в 300 нм [60] было высказано предположение о каталитическом механизме хемостимулирующего действия. Далее было установлено, что при уменьшении толщины слоя оксида ванадия на порядок (с 300 до 15-25 нм) изменения ЭЭА практически не происходит, таким образом, независимость значений ЭЭА безусловно свидетельствуют в пользу каталитического механизма.
В случае оксидирования $\mathrm{V}_{2} \mathrm{O}_{5} / \mathrm{InP}(\mathrm{GaAs})$ наблюдается малый расход катализатора $\mathrm{V}_{2} \mathrm{O}_{5}$ в течение термооксидирования [61], свидетельствующий о его регенерации в каталитическом цикле $\mathrm{V}^{4+} \leftrightarrow \mathrm{V}^{5+}$. Это подтверждается и термодинамическими расчетами. Реакция передачи кислорода с образованием металлического ванадия гораздо менее энергетически выгодна в сравнении с реакцией перехода $\mathrm{V}_{2} \mathrm{O}_{5}$ в $\mathrm{VO}_{2}$ :

$$
\begin{gathered}
2 \mathrm{In}+3 / 5 \mathrm{~V}_{2} \mathrm{O}_{5}=\mathrm{In}_{2} \mathrm{O}_{3}+6 / 5 \mathrm{~V}, \\
\Delta G^{800}=-80.56 \text { кДж/моль, } \\
2 \mathrm{In}+3 \mathrm{~V}_{2} \mathrm{O}_{5}=\mathrm{In}_{2} \mathrm{O}_{3}+6 \mathrm{VO}_{2}, \\
\Delta G^{800}=-706.7 \text { кДж/моль, } \\
2 \mathrm{Ga}+3 \mathrm{~V}_{2} \mathrm{O}_{5}=\mathrm{Ga}_{2} \mathrm{O}_{3}+6 \mathrm{VO}_{2}, \\
\Delta G^{800}=-681.1 \text { кДж/моль. }
\end{gathered}
$$

Кроме реакций $(6,7)$ возможно осуществление и процессов:

$$
\begin{gathered}
2 \mathrm{P}+5 \mathrm{~V}_{2} \mathrm{O}_{5}=\mathrm{P}_{2} \mathrm{O}_{5}+10 \mathrm{VO}_{2}, \\
\Delta G^{800}=-842.67 \text { кДж/моль, } \\
2 \mathrm{As}+5 \mathrm{~V}_{2} \mathrm{O}_{5}=\mathrm{As}_{2} \mathrm{O}_{5}+10 \mathrm{VO}_{2}, \\
\Delta G^{500}=-236.66 \text { кДж/моль }
\end{gathered}
$$

Методами РФА и ИКС в течение всего процесса оксидирования $\mathrm{V}_{2} \mathrm{O}_{5} / \mathrm{InP}(\mathrm{GaAs})$ фиксируется наличие в формирующихся пленках оксидов ванадия $\mathrm{V}_{2} \mathrm{O}_{5}$ и $\mathrm{VO}_{2}$ (табл. 7), то есть фактически подтверждается стадия циклической регенерации $\mathrm{V}_{2} \mathrm{O}_{5}[47]$ :

$$
\mathrm{V}_{2} \mathrm{O}_{5} \rightarrow \mathrm{V}_{3} \mathrm{O}_{7} \rightarrow \mathrm{V}_{4} \mathrm{O}_{9} \rightarrow \mathrm{V}_{6} \mathrm{O}_{13} \rightarrow \mathrm{VO}_{2}
$$

Для $\mathrm{V}_{4} \mathrm{O}_{9}$ характерна одна короткая связь $\mathrm{V}-\mathrm{O}$ в интервале $0.16-0.165$ нм, четыре связи в интервале 0.187-0.202 нм и одна длинная связь, которая 
Таблица 7. Состав пленок, сформированных оксидированием гетероструктур $\mathrm{V}_{2} \mathrm{O}_{5} / \mathrm{GaAs}(\operatorname{InP})$ (жёсткий метод, данные ИКС, РФА)

[Table 7. Composition of films formed by oxidation of $\mathrm{V}_{2} \mathrm{O}_{5} / \mathrm{GaAs}(\mathrm{InP})$ heterostructures (hard method, IRS, XRD data)]

\begin{tabular}{|c|c|c|c|c|}
\hline \multirow{2}{*}{$\begin{array}{l}\text { Гетероструктура } \\
\text { [Heterostructure] }\end{array}$} & \multicolumn{2}{|c|}{$\begin{array}{l}\text { Режим оксидирования } \\
\text { [Oxidation condition] }\end{array}$} & \multicolumn{2}{|c|}{$\begin{array}{c}\text { Идентифицированные соединения } \\
\text { [Identified compounds] }\end{array}$} \\
\hline & $T,{ }^{\circ} \mathrm{C}$ & $\begin{array}{c}\tau, \text { мин. } \\
{[\tau, \text { min }]}\end{array}$ & ИКС [IRS] & РФА [XRD] \\
\hline \multirow{4}{*}{$\mathrm{V}_{2} \mathrm{O}_{5}(25 \mathrm{HM}[\mathrm{nm}]) / \mathrm{InP}$} & 20 & 0 & $\operatorname{InP}, \mathrm{In}_{2} \mathrm{O}_{3}, \mathrm{~V}_{2} \mathrm{O}_{5}$ & $\mathrm{~V}_{2} \mathrm{O}_{5}$ \\
\hline & 480 & 60 & $\begin{array}{c}\mathrm{InP}, \mathrm{In}_{2} \mathrm{O}_{3} \mathrm{InPO}_{4} \\
\mathrm{In}\left(\mathrm{PO}_{3}\right)_{3}, \mathrm{~V}_{2} \mathrm{O}_{5},\left[\mathrm{VO}_{4}\right]^{3-} \\
\alpha-\mathrm{VO}\left(\mathrm{PO}_{3}\right)_{3},(\mathrm{VO})_{2} \mathrm{P}_{2} \mathrm{O}_{7}\end{array}$ & $\begin{array}{c}\text { InP, } \operatorname{InPO}, \operatorname{In}\left(\mathrm{PO}_{3}\right)_{3}, \\
\mathrm{~V}_{2} \mathrm{O}_{5}, \mathrm{VO}_{2},\end{array}$ \\
\hline & 520 & 60 & $\begin{array}{c}\mathrm{InP}, \mathrm{In}_{2} \mathrm{O}_{3} \mathrm{InPO}_{4} \\
\left.\mathrm{In}\left(\mathrm{PO}_{3}\right)_{3}, \mathrm{~V}_{2} \mathrm{O}_{5}, \mathrm{VO}_{4}\right]^{3-} \\
\alpha-\mathrm{VO}\left(\mathrm{PO}_{3}\right)_{3},(\mathrm{VO})_{2} \mathrm{P}_{2} \mathrm{O}_{7}\end{array}$ & $\begin{array}{c}\mathrm{InP}, \mathrm{InPO}_{4}, \mathrm{In}\left(\mathrm{PO}_{3}\right)_{3}, \\
\mathrm{~V}_{2} \mathrm{O}_{5}, \mathrm{VO}_{2}\end{array}$ \\
\hline & 560 & 60 & $\begin{array}{c}\mathrm{InP}, \mathrm{In}_{2} \mathrm{O}_{3} \mathrm{InPO}_{4}, \\
\mathrm{In}\left(\mathrm{PO}_{3}\right)_{3}, \mathrm{~V}_{2} \mathrm{O}_{5},\left[\mathrm{VO}_{4}\right]^{3-} \\
\alpha-\mathrm{VO}\left(\mathrm{PO}_{3}\right)_{3},(\mathrm{VO})_{2} \mathrm{P}_{2} \mathrm{O}_{7}\end{array}$ & $\begin{array}{l}\text { InP, } \mathrm{InPO}_{4}, \mathrm{In}\left(\mathrm{PO}_{3}\right)_{3}, \\
\mathrm{~V}_{2} \mathrm{O}_{5}, \mathrm{VO}_{2},\end{array}$ \\
\hline \multirow{3}{*}{$\mathrm{V}_{2} \mathrm{O}_{5}(25 \mathrm{HM}[\mathrm{nm}]) / \mathrm{GaAs}$} & 20 & 0 & $\mathrm{GaAs}, \mathrm{Ga}_{2} \mathrm{O}_{3}, \mathrm{~V}_{2} \mathrm{O}_{5}$ & $\mathrm{~V}_{2} \mathrm{O}_{5}$ \\
\hline & 480 & 60 & $\begin{array}{c}\text { GaAs, } \mathrm{Ga}_{2} \mathrm{O}_{3}, \mathrm{As}_{2} \mathrm{O}_{3},\left[\mathrm{AsO}_{4}\right]^{3}, \\
\mathrm{~V}_{2} \mathrm{O}_{5,}\left[\mathrm{VO}_{4}\right]^{3-}\end{array}$ & $\begin{array}{l}\mathrm{VO}_{2}, \mathrm{~V}_{4} \mathrm{O}_{9}, \mathrm{~V}_{3} \mathrm{O}_{7} \\
\mathrm{~V}_{2} \mathrm{O}_{5}, \mathrm{Ga}_{2} \mathrm{O}_{3}, \mathrm{As}_{2} \mathrm{O}_{3}\end{array}$ \\
\hline & 560 & 60 & $\begin{array}{c}\text { GaAs, } \mathrm{Ga}_{2} \mathrm{O}_{3}, \mathrm{As}_{2} \mathrm{O}_{3},\left[\mathrm{AsO}_{4}\right]^{3}, \\
\mathrm{~V}_{2} \mathrm{O}_{5,}\left[\mathrm{VO}_{4}\right]^{3-}\end{array}$ & $\begin{array}{l}\mathrm{VO}_{2}, \mathrm{~V}_{4} \mathrm{O}_{9}, \mathrm{~V}_{3} \mathrm{O}_{7} \\
\mathrm{~V}_{2} \mathrm{O}_{5}, \mathrm{Ga}_{2} \mathrm{O}_{3}, \mathrm{As}_{2} \mathrm{O}_{3}\end{array}$ \\
\hline
\end{tabular}

для четырех неэквивалентных атомов ванадия равна $0.223,0.240,0.250$ и 0.300 нм, то есть фактически $1 / 4$ часть атомов ванадия имеет координационное число 5, более характерное для пентаоксида ванадия [62]. Для оксида $\mathrm{V}_{3} \mathrm{O}_{7}$ из 36 атомов ванадия в элементарной ячейке 12 имеют октаэдрическую координацию, 16 - окружение в виде тригональной бипирамиды, 8 - в виде квадратной пирамиды, так что формулу этого оксида можно выразить как $\mathrm{V}^{4+} \mathrm{V}_{2}{ }^{5+} \mathrm{O}_{7}$. Такие

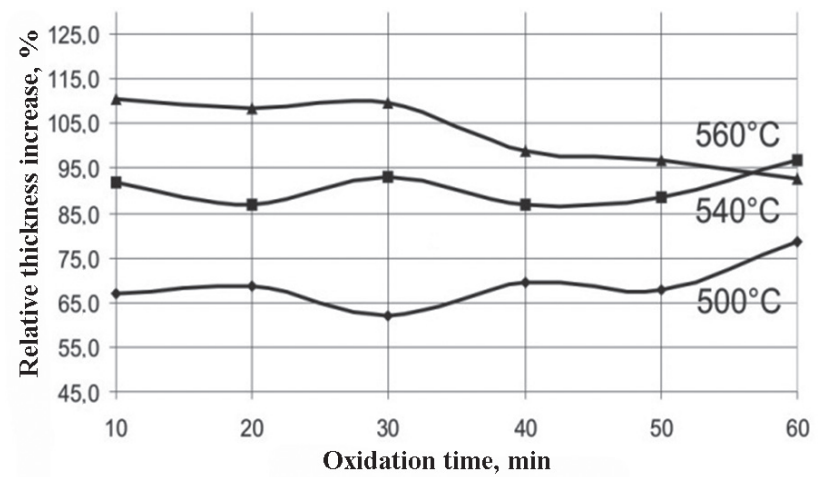

$a$ превращения, характерные для оксидов с неправильной структурой, несимметричным расположением ионов кислорода вокруг иона металла, рыхлой упаковкой, не требуют глубокой перестройки всей кристаллической решетки, протекают очень быстро с малыми затратами энергии.

Динамика изменения относительного прироста толщин пленок с развитием процесса во времени (рис. 8) также говорит о каталитическом типе воз-

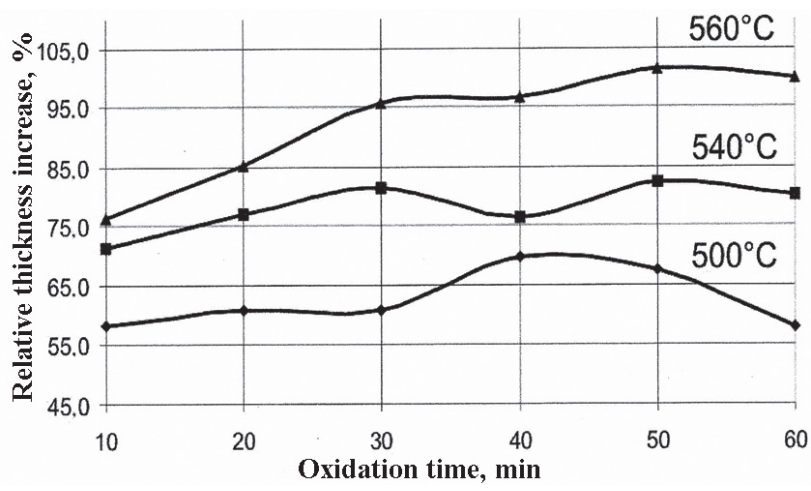

$b$

Рис. 8. Относительный прирост толщины пленок в процессах оксидирования гетероструктур $\mathrm{V}_{2} \mathrm{O}_{5}(25 \mathrm{Hм}) / \mathrm{InP}$ (a) и $\mathrm{V}_{2} \mathrm{O}_{5}(25 \mathrm{Hм}) / \mathrm{GaAs}(b)$ при различных температурах по сравнению с собственным оксидированием полупроводников

[Fig. 8. Relative increase in film thickness in the processes of oxidation of

$\mathrm{V}_{2} \mathrm{O}_{5}(25 \mathrm{~nm}) / \mathrm{InP}(a)$ and $\mathrm{V}_{2} \mathrm{O}_{5}(25 \mathrm{~nm}) / \mathrm{GaAs}(b)$ heterostructures at different temperatures in comparison with the own oxidation of semiconductors] 
действия магнетронно нанесённого $\mathrm{V}_{2} \mathrm{O}_{5}$. Ярко выраженное постоянство этой величины во времени, а также ее практическая независимость от толщины слоя нанесенного $\mathrm{V}_{2} \mathrm{O}_{5}$ (рис. $8 a, b$ ) доказывает регенерацию хемостимулятора $\mathrm{V}_{2} \mathrm{O}_{5}$ и, соответственно, каталитический механизм его действия.

В случае процесса, протекающего по транзитному механизму, форма кривых относительного прироста толщины пленок проходит через максимум при небольших временах оксидирования и завершается спадом на развитом этапе процесса (рис. 9). Так, на кривых относительного прироста толщины пленок, формируемых оксидированием $\mathrm{Co}_{3} \mathrm{O}_{4} / \mathrm{InP}$, на начальном этапе процесса (до 15 мин при $T=550{ }^{\circ} \mathrm{C}$ ) наблюдается резкий максимум (до $80 \%$ ), который на развитом этапе процесса сменяется значительным спадом до 35-40 \%, характерным для транзитного механизма оксидирования.

Это связано с расходом транзитора за счет протекания транзитных взаимодействий, связывания его в устойчивые соединения (фосфаты) и некоторой диффузии выделившегося в ходе транзита металла в полупроводниковую подложку, и, соответственно, уменьшением хемостимулирующего эффекта с течением процесса.

Каталитический механизм действия $\mathrm{V}_{2} \mathrm{O}_{5}$ в процессах оксидирования InP и GaAs подтверждает и практическая независимость кинетических параметров процессов (табл. 5) от природы подложки. При отсутствии негативного влияния переходной области $\mathrm{Me}_{\mathrm{x}} \mathrm{A}_{\mathrm{y}}{ }_{\mathrm{II}} \mathrm{B}_{\mathrm{z}}^{\mathrm{V}}$ на границе раздела металл/полупроводник проявляется универсальность используемого хемостимулятора как ката-

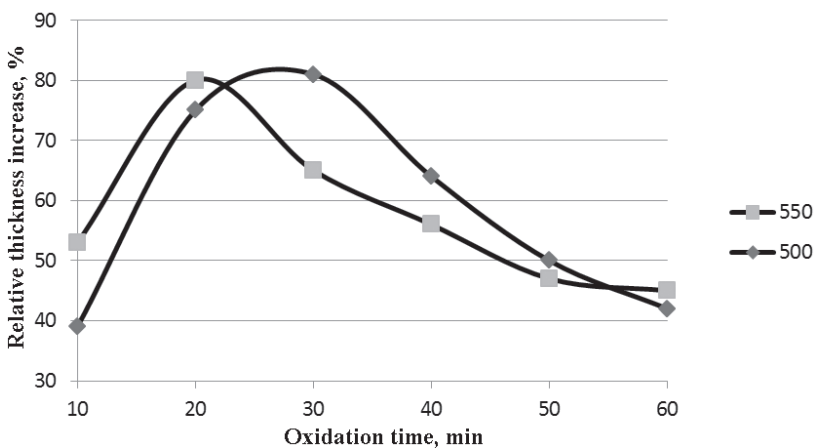

Рис. 9. Относительный прирост толщины пленок в процессе оксидирования гетероструктуры $\mathrm{Co}_{3} \mathrm{O}_{4} / \mathrm{InP}$ при различных температурах по сравнению с собственным оксидированием InP

[Fig. 9. The relative increase in the thickness of films during the oxidation of the $\mathrm{Co}_{3} \mathrm{O}_{4} / \mathrm{InP}$ heterostructure at different temperatures in comparison with the own oxidation of $\mathrm{InP}]$

лизатора оксидирования бинарных полупроводников $\mathrm{A}^{\mathrm{III}} \mathrm{B}^{\mathrm{V}}$. Схема механизма оксидирования $\mathrm{V}_{2} \mathrm{O}_{5} /$ $\mathrm{A}^{\mathrm{III}} \mathrm{B}^{\mathrm{V}}$ на примере гетероструктуры $\mathrm{V}_{2} \mathrm{O}_{5} / \mathrm{InP}$ представлена на рис. 10.

С точки зрения кинетических характеристик интересен процесс оксидирования гетероструктуры $\mathrm{Co}_{3} \mathrm{O}_{4} / \mathrm{InP}$ с низкими значениями ЭЭА на первом этапе и высокими - на втором (табл. 5). При оксидировании $\mathrm{Co}_{3} \mathrm{O}_{4} / \mathrm{InP}$ термодинамически процесс может протекать с аналогичным энергетическим выигрышем, что и оксидирование $\operatorname{InP}$ с нанесенным наноразмерным слоем $\mathrm{V}_{2} \mathrm{O}_{5}$ :

$$
\begin{gathered}
3 \mathrm{Co}_{3} \mathrm{O}_{4}+8 \mathrm{In}=9 \mathrm{Co}+4 \operatorname{In}_{2} \mathrm{O}_{3} \Delta G^{800}= \\
=-32.56 \text { кДж/моль }
\end{gathered}
$$

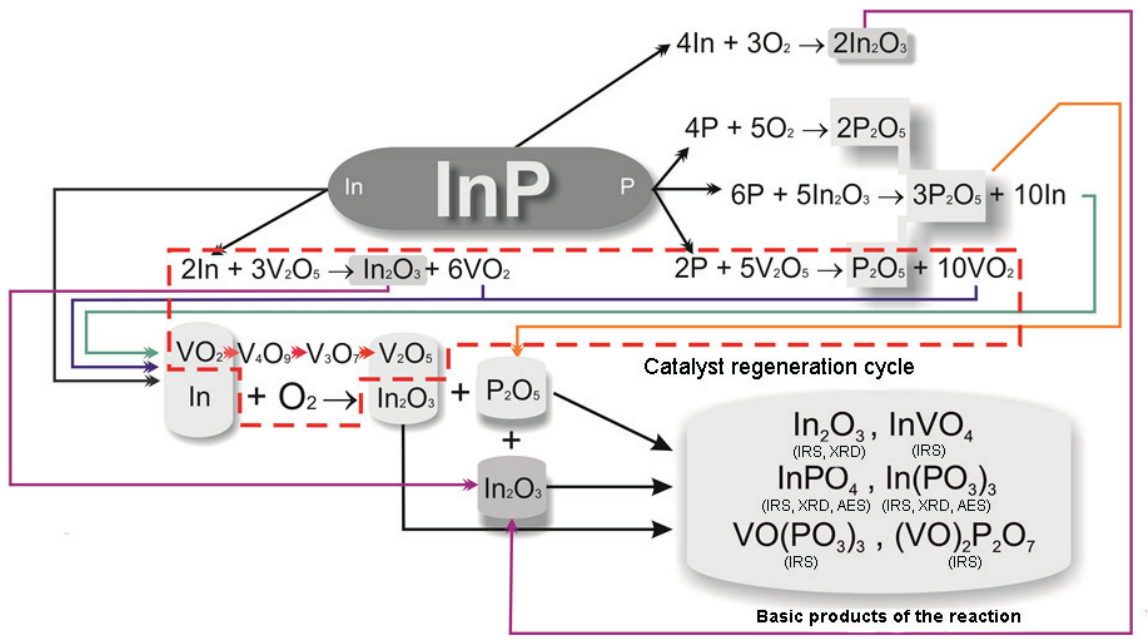

Рис. 10. Схема химических превращений при термооксидировании гетероструктуры $\mathrm{V}_{2} \mathrm{O}_{5} / \mathrm{InP}$

[Fig. 10. Scheme of chemical transformations during thermal oxidation of a $\mathrm{V}_{2} \mathrm{O}_{5} / \mathrm{InP}$ heterostructure] 


$$
\begin{gathered}
3 \mathrm{Co}_{3} \mathrm{O}_{4}+2 \mathrm{In}=9 \mathrm{CoO}+\operatorname{In}_{2} \mathrm{O}_{3} \Delta \mathrm{G}^{800}= \\
=-580.30 \text { кДж/моль }
\end{gathered}
$$

Предпосылки проявления оксидом $\mathrm{Co}_{3} \mathrm{O}_{4}$ каталитической активности в процессе оксидирования InP выражаются в низкой ЭЭА (60 кДж/моль), но только на первом этапе оксидирования. В дальнейшем начинают преобладать затруднения различной природы, и, прежде всего, затруднённая перестройка кристаллической структуры при переходе $\mathrm{CoO}$ в $\mathrm{Co}_{3} \mathrm{O}_{4}$ и обратно. Об этом свидетельствуют и зависимости относительного прироста толщины пленок, формируемых оксидированием $\mathrm{Co}_{3} \mathrm{O}_{4} / \mathrm{InP}$, от времени процесса (см. рис. 9).

Таким образом, каталитический механизм действия магнетронно нанесённого $\mathrm{V}_{2} \mathrm{O}_{5}$ (жёсткий способ) в процессах оксидирования фосфида индия и арсенида галлия обусловлен, прежде всего, химической природой пентаоксида ванадия, электронной конфигурацией $d$-металла и ковалентным типом химических связей ванадия с кислородом, способностью легко и обратимо переходить из степени окисления +5 в +4 (за счет неправильной структуры, несимметричного расположения ионов кислорода вокруг ионов металла, рыхлости в упаковке металл-кислородных полиэдров) $[47,62]$.

Морфология поверхности сформированных оксидированием $d-\mathrm{MeO} / \mathrm{GaAs}(\mathrm{InP})$ пленок отражает структуры с низкой шероховатостью с латеральными размерами неоднородностей в интервале 200 300 нм. Максимальный перепад высот рельефа таких пленок составляет 18-24 нм, значения среднеарифметической и среднеквадратичной шероховатости весьма малы по величине -1.64 и 2.38 нм соответственно.

Исследование ряда оптических характеристик образцов, формируемых в процессе хемостимулированного синтеза наноразмерных пленок на InP, методом спектральной эллипсометрии (СЭ) позволяет сделать определенные выводы [63-65]. Показатель поглощения $k$ для собственного оксида на InP достигает значения 0.3 , что связано с самим механизмом термооксидирования полупроводника и появлением неокисленного индия в пленках за счет реализации отрицательного канала связи между реакциями покомпонентного окисления. При этом объёмное содержание индия в собственном оксиде, определенное методом спектральной эллипсометрии с использованием модели гетерогенной среды, составляет порядка 8 \%, что коррелирует с результатами электрофизических измерений, показывающих наличие омической проводимости таких пленок.
Жесткий же метод магнетронного нанесения хемостимуляторов на поверхность $\mathrm{A}^{\mathrm{III}} \mathrm{B}^{\mathrm{V}}$ способствует формированию хемостимулированным синтезом слабопоглощающих в диапазоне длин волн 420-900 см-1 наноразмерных пленок, для которых зависимости $n(\lambda)$ и $k(\lambda)$ в длинноволновой области имеют классическую для диэлектриков дисперсию. Очень малое поглощение - например, для образца $\mathrm{V}_{2} \mathrm{O}_{5} / \mathrm{InP}$, оксидированного в режиме $500^{\circ} \mathrm{C}$, 60 мин, равное 0.02 , - согласно модели гетерогенной среды интерпретируется включениями индия на уровне до $0.5 \%$.

Как уже было сказано выше, нанесение пентаоксида ванадия мягкими методами (в рамках одного способа - нанесение на поверхность до начала процесса термооксидирования) приводит к реализации транзитного механизма термооксидирования полупроводника. Уникальность оксида ванадия заключается в том, что нанесение слоёв возможно мягкими методами, в частности, с использованием золь-гель технологии. Очень часто в данном случае для синтеза плёнок оксидов ванадия используются металлоорганические соединения, такие как $\mathrm{VO}\left(\mathrm{OC}_{3} \mathrm{H}_{7}\right)_{3}$, триэтоксиванадил $[14,66]$ в различных растворителях. При этом установлено, что фазовый состав синтезированных плёнок, их морфология и свойства зависят от большого числа факторов - от использования разнообразных прекурсоров и растворителей (влияние оказывают концентрация исходного раствора, режим осаждения), вида и условий последующей сушки и отжига (окислительного или восстановительного).

Возможность получения геля и золя пентаоксида ванадия позволяет осаждать его на поверхность $\mathrm{A}^{\mathrm{II}} \mathrm{B}^{\mathrm{V}}$, используя различные подходы: центрифугирование, осаждение из аэрозоля и т.д., что и было реализовано авторами данного обзора [67]. Развитие процесса оксидирования и характеристики формируемых в результате плёнок во многом определяются видом отжига - термического или импульсного фотонного. Так, осаждение геля $\mathrm{V}_{2} \mathrm{O}_{5}$ из аэрозоля с последующим термическим отжигом приводит к формированию гладких плёнок. Режимы термического отжига в данном случае подбираются таким образом, чтобы при выбранной температуре не происходило взаимодействие «пленкаподложка» до начала термооксидирования, то есть, чтобы метод оставался мягким в указанной выше классификации. Варьирование режима отжига позволяет изменять содержание различных оксидных форм ванадия в нанесенном слое. Импульсная фотонная обработка гетероструктур $\mathrm{V}_{\mathrm{x}} \mathrm{O}_{\mathrm{y}} / \mathrm{InP}$, сфор- 
мированных диспергированием геля пентаоксида ванадия, является более эффективной как с точки зрения технологичности процесса (значительное сокращение затрат времени и энергии по сравнению с термическим отжигом), так и с точки зрения существенного увеличения скорости роста оксидных пленок в процессе термооксидирования данных гетероструктур по сравнению с термически отожженными. Кроме того, импульсная фотонная обработка приводит к более эффективной и быстрой кристаллизации аморфной фазы геля $\mathrm{V}_{2} \mathrm{O}_{5}$ по сравнению с термической обработкой. Однако в данном случае назвать такой метод мягким уже нельзя: в процессе фотонного отжига начинается взаимодействие полупроводниковой подложки с нанесенным хемостимулятором, что характерно для жестких методов нанесения (магнетронное напыление и т. д.).

Рассчитанные с использованием данных лазерной эллипсометрии значения ЭЭА оксидирования сформированных мягким методом и прошедших термический отжиг гетероструктур $\mathrm{V}_{\mathrm{x}} \mathrm{O}_{\mathrm{y}} / \mathrm{A}^{\mathrm{III}} \mathrm{B}^{\mathrm{V}}$ (210 кДж/моль для InP и 77 кДж/моль для GaAs) свидетельствуют о реализации транзитного механизма процесса. Расходование $\mathrm{V}_{2} \mathrm{O}_{5}$ в процессе термооксидирования подтверждает транзитный характер действия хемостимулятора, поскольку необходимый для протекания катализа цикл регенерации $\mathrm{V}^{+5} \leftrightarrow \mathrm{V}^{+4}$ не осуществляется.

При оксидировании тонкопленочных структур с хемостимулятором, нанесенным мягким методом, процесс одноэтапен, и протекающие реакции таковы:

В плёнке вблизи внутренней границы раздела

$$
\begin{aligned}
& 2 \mathrm{In}+3 \mathrm{~V}_{2} \mathrm{O}_{5}=\mathrm{In}_{2} \mathrm{O}_{3}+6 \mathrm{VO}_{2} \\
& 2 \mathrm{P}+5 \mathrm{~V}_{2} \mathrm{O}_{5}=\mathrm{P}_{2} \mathrm{O}_{5}+10 \mathrm{VO}_{2},
\end{aligned}
$$

активный в момент выделения $\mathrm{VO}_{2}$ быстро окисляется. Однако появляется ещё одна стадия

$$
\mathrm{In}_{2} \mathrm{O}_{3}+\mathrm{V}_{2} \mathrm{O}_{5}=2 \mathrm{InVO}_{4},
$$

приводящая к связыванию хемостимулятора с образованием InVO $\mathrm{V}_{4}$ и частичному выводу его из зоны реакции. Причина заключается в том, что жесткий метод позволяет создать соответствующие поверхностные комплексы уже на стадии нанесения хемостимулятора. При использовании мягкого метода образование таких комплексов затруднено, и каталитический механизм в конечном итоге не реализуется.

В нанесенном мягким методом слое хемостимулятора присутствуют низшие оксиды ванадия, т. к. пентаоксид выводится из зоны реакции, а эти низшие формы практически не вступают в транзит. Они могли бы доокисляться до $\mathrm{V}_{2} \mathrm{O}_{5}$, но кислород преимущественно расходуется на окисление индия и фосфора.

Таким образом, создание условий для синхронного каталитического механизма возможно в условиях сплошной границы, сформированной жестким способом, когда эта граница выступает как единый «навязанный» поверхностный комплекс.

\section{V. ЗАКЛЮЧЕНИЕ}

Установлено, что использование оксидов в качестве хемостимуляторов термического оксидирования $\mathrm{A}^{\mathrm{III}} \mathrm{B}^{\mathrm{V}}$ изменяет механизм процесса термооксидирования полупроводников с собственного на транзитный либо каталитический. Основными факторами, определяющими механизм хемостимулирующего воздействия, являются химическая природа оксида-хемостимулятора и способ его введения в систему. Оксиды $p$-металлов ( $\left.\mathrm{PbO}, \mathrm{Sb}_{2} \mathrm{O}_{3}, \mathrm{Bi}_{2} \mathrm{O}_{3}\right)$, имеющих преимущественно одну устойчивую степень окисления, независимо от способа их введения в систему (из газовой фазы либо нанесение на поверхность полупроводника) реализуют транзитный механизм оксидирования GaAs и InP. Оксиды $d$-металлов, имеющих несколько устойчивых степеней окисления (марганца и ванадия), вводимые в систему через газовую фазу, а также оксиды $\mathrm{NiO}$ и $\mathrm{Co}_{3} \mathrm{O}_{4}$, наносимые на поверхность $\mathrm{A}^{\mathrm{III}} \mathrm{B}^{\mathrm{V}}$ и имеющие преимущественно одну устойчивую степень окисления, воздействуют в процессах термооксидирования как хемостимуляторы-транзиторы. Резкое снижение ЭЭА оксидирования гетероструктур $\mathrm{V}_{2} \mathrm{O}_{5} / \mathrm{InP}$ и $\mathrm{V}_{2} \mathrm{O}_{5} / \mathrm{GaAs}$ в сравнении со значениями этой величины, характерными для процессов, протекающих по транзитному механизму, независимость значения ЭЭА от толщины нанесенного слоя $\mathrm{V}_{2} \mathrm{O}_{5}$, циклическая регенерация ванадия $\mathrm{V}^{5+} \leftrightarrow \mathrm{V}^{4+}$, динамика изменения относительного прироста толщины пленок говорят о реализации взаимодействия $\mathrm{V}_{2} \mathrm{O}_{5}$ с компонентами полупроводниковых подложек по каталитическому типу. Именно для этих случаев фиксируются интенсивные процессы фосфато- и арсенатообразования при низких (450-480 ${ }^{\circ} \mathrm{C}$ ) температурах, эффективная кинетическая и химическая блокировка диффузии неокисленного индия в пленку (содержание индия 0.3-0.5\%, данные СЭ) и предотвращение сегрегации мышьяка на внутренней границе раздела. Всё это приводит к значительному улучшению электрофизических параметров пленок вышеописанными способами. 
Результаты исследований получены на оборудовании Центра коллективного пользования Воронежского государственного университета. URL: http://ckp.vsu.ru
Работа выполнена при поддержке гранта

РФФИ № 16-43-360595 p_a

\title{
THERMAL OXIDATION AS A METHOD OF FORMATION OF NANOSCALE FUNCTIONAL FILMS ON A A $^{\mathrm{II}} \mathrm{B}^{\mathrm{V}}$ SEMICONDUCTORS: CHEMOSTIMULATED INFLUENCE OF METAL OXIDES OVERVIEW
}

\author{
(C) 2018 E. V. Tomina, I. Ya. Mittova, B. V. Sladkopevtsev, V. F. Kostryukov, A. A. Samsonov, \\ N. N. Tretyakov \\ Voronezh State University, 1 Universitetskaya pl., 394018 Voronezh, Russia \\ e-mail: tomina-e-v@yandex.ru
}

Received 04.05.2018

\begin{abstract}
The use of oxides as chemostimulators of $\mathrm{A}^{\mathrm{III}} \mathrm{B}^{\mathrm{V}}$ thermal oxidation alters the mechanism of the process of thermal oxidation of semiconductors from its own to that of transit or catalytic. The mechanism of the process is determined by the chemical nature of the oxide-chemostimulator and the way it is introduced into the system (from the gas phase or deposition on the semiconductor surface).

The oxides of $p$-metal $\left(\mathrm{PbO}, \mathrm{Sb}_{2} \mathrm{O}_{3}, \mathrm{Bi}_{2} \mathrm{O}_{3}\right)$, having predominantly one stable oxidation state, realize a transit mechanism of semiconductors oxidation, regardless of the way they are introduced into the system. The oxides of $d$-metals $\left(\mathrm{MnO}_{2}, \mathrm{~V}_{2} \mathrm{O}_{5}, \mathrm{CrO}_{3}\right)$ introduced through the gas phase act on the processes of thermal oxidation of $\mathrm{GaAs}$ and $\mathrm{InP}$ as the chemostimulator-transitors. The effect of nanosized $\mathrm{NiO}$ and $\mathrm{Co}_{3} \mathrm{O}_{4}$ layers in the processes of $\mathrm{InP}$ and $\mathrm{GaAs}$ thermal oxidation develops as a transit type, which is confirmed by EEA values, which are of the same order of magnitude as the EEA of own oxidation of semiconductors, the consumption of oxide-chemostimulators with the passing of the process in time, a significant decrease in the relative increase in film thickness during the advanced stage of the process.

For nanosized layers of vanadium oxide $(\mathrm{V})$ the mechanism of their effect on the process of oxidation of $\mathrm{A}^{\mathrm{III}} \mathrm{B}^{\mathrm{V}}$ is determined to a large extent by the deposition method (within the framework of one way). Thermal oxidation of $\mathrm{A}^{\mathrm{III}} \mathrm{B}^{\mathrm{V}}$ under the influence of vanadium pentoxide layers deposited by soft methods implements the transit mechanism of the process, this is indicated by the expenditure of $\mathrm{V}_{2} \mathrm{O}_{5}$ in films during thermal oxidation without subsequent regeneration. The catalytic nature of the effect of the magnetron-deposited (hard method) layers of $\mathrm{V}_{2} \mathrm{O}_{5}$ in the oxidation processes of InP and GaAs is confirmed by a sharp decrease in EEA in comparison with the own oxidation of semiconductors and the independence of its value from the thickness of the deposited $\mathrm{V}_{2} \mathrm{O}_{5}$ layer, the cyclic regeneration of vanadium $\mathrm{V}^{5+} \leftrightarrow \mathrm{V}^{4+}$, and the dynamics of the change in the relative increase in film thicknesses. In this case, the processes of phosphate and arsenate formation take place at low temperatures (450$480^{\circ} \mathrm{C}$ ), an effective kinetic and chemical blocking of the diffusion of unoxidized indium into a film occurs, and segregation of arsenic at the inner interface prevented. All of the above leads to a significant improvement in the electrophysical parameters of the films.
\end{abstract}

Keywords: indium phosphide, gallium arsenide, thermal oxidation, chemostimulator, nanosized films.

DOI: https://doi.org/10.17308/kcmf.2018.20/522 


\section{ACKNOWLEDGMENTS}

The research results were obtained using the equipment of the Center for Collective Use of Equipment Voronezh State University. URL: http://ckp.vsu.ru

The reported study was supported by a grant from the Russian Foundation for Basic Research (project No. 16-43-360595 p_a)

\section{REFERENCES}

1. Mittova I. Ya. Inorganic Materials, 2014, vol. 50, no. 9, pp. 874-881. DOI: 10.1134/S0020168514090088

2. Tomina E. V. Chemical Stimulated Oxidation of GaAs and InP Under the Influence of d-metals (Ni, Co, V), their Oxides and the Compositions of Oxides. Diss. doct. chem. sci. Voronezh, 2017, 342 p. (in Russ.)

3. Tomina E. V., Mittova I. Ya., Zelenina L. S. Condensed Matter and Interphase, 2018, vol. 20, no. 1, pp. 6-24. DOI: 10.17308/kcmf.2018.20/472. (in Russ.)

4. Mittova I. Ya., Tomina E. V., Lapenko A. A., Sladkopevtsev B. V. Nanosystems: Physics, Chemistry, Mathematics, 2012, vol. 3, no. 2, pp. 116-138. (in Russ.)

5. Ievlev V. M., Mittova I. Ya., Samsonov A. A., Tomina E. V., Kashkarov V. M. Doklady Chemistry, 2007, vol. 417, no. 2, pp. 277-281. DOI: 10.1134/S0012500807120014

6. Mittova I. Ya., Tomina E. V., Lapenko A. A., Sladkopevtsev B. V. Glass Physics and Chemistry, 2011, vol. 37, no. 2, pp. 230-234. DOI: 10.1134/S1087659611020106

7. Sladkopevtsev B. V., Lapenko A. A., Samsonov A. A., Tomina E. V., Mittova I. Ya. Condensed Matter and Interphase, 2010, vol. 12, no. 3, pp. 268-275. Available at: http://www. kcmf.vsu.ru/resources/t 12 3 2010_009.pdf (in Russ.)

8. Mittova I. Ya., Tomina E. V., Tretyakov N. N., Sladkopevtsev B. V. Condensed Matter and Interphase, 2013, vol. 15 , no. 3, pp. 305-311. Available at: http://www.kcmf. vsu.ru/resources/t_15_3_2013_013.pdf (in Russ.)

9. Kostryukov V. F., Mittova I. Ya. Patent RF, no. 2538415, 2015. (in Russ.)

10. Qing Su., Xiaojun Pan, Erqing Xie, Yinyue Wang, Jiawen Qiu, Xueqin Liu Rare Metals, vol. 25, no. 6, p. 8287. DOI: 10.1016/S1001-0521(07)60050-3

11. Deepak Raj P., Sudha Gupta, Sridharan M. Ceramics International, vol. 43, no. 12, pp. 9401-9407. DOI: 10.1016/j.ceramint.2017.04.110.

12. Pervikov A., Lerner M. Current Applied Physics, vol. 17 , no. 11 , pp. 1494-1500. DOI: $10.1016 /$ j. cap.2017.08.017.

13. Lerner M. I., Shimanskiy V. V., Saveliev G. G. Bulletin of the Toмsк Polytechnic University., 2007, vol. 310, no. 2, pp. 122-126. Available at: http://www.lib.tpu.ru/fulltext/v/Bulletin_TPU/2007/v310eng/i2/29.pdf

14. Vinichenko D. A., Zlomanon V. P., Vasil'ev V. A., Seregin D. S., Berezina O. Ya. Inorganic Materials, 2011, vol. 47, no. 3, pp. 279-284. DOI: 10.1134/ S0020168511030216

15. Yakovleva D., Pergament A., Berezina O., Boriskov P., Kirienko D., Pikulev V. Materials Science in Semi- conductor Processing, 2016, vol. 44, pp. 78-84. DOI: 10.1016/j.mssp.2016.01.003.

16. Berezina O., Kirienko D., Pergament A., Stefanovich G., Velichko A., Zlomanov V. Thin Solid Films, 2015, vol. 574, pp. 15-19. DOI: 10.1016/j.tsf.2014.11.058

17. Vernardou D., Pemble M. E., Sheel D. W. Surface and Coatings Technology, 2004, vol. 188-189, pp. 250-254. DOI: 10.1016/j.surfcoat.2004.08.037.

18. Mittova I. Ya. Vestnik VGU. Serija: Himija, biologija [Bulletin of the VSU. Series: Chemistry, Biology], 2000, no. 2, pp. 5-12. (in Russ.)

19. Ienlev V. M. Tonkie plenki neorganicheskih materialov: mehanizm rosta i struktura. [Thin Films of Inorganic Materials: Growth Mechanism and Structure]. Voronezh, VSU Publ., 2008, 496 p. (in Russ.)

20. Mittova I. Ya., Tomina E. V., Sladkopevtsev B. V., Dontsov A. I. Journal of Surface Investigation. X-ray, Synchrotron and Neutron Techniques, 2014, vol. 8, no. 5, pp. 941-949. DOI: 10.1134/S1027451014050140

21. Mittova I. Ya., Tomina E. V., Sladkopevtcev B. V. Nanosystems: Physics, Chemistry, Mathematics, 2014, vol. 5, no. 2, pp. 307-314. Available at: http://nanojournal. ifmo.ru/en/articles-2/volume5/5-2/chemistry/paper07/

22. Mittova I. Ya., Tomina E. V., Sladkopevtcev B. V., Samsonov A. A. Condensed Matter and Interphase, 2014, vol. 16, no 1, pp. 60-66. Available at: http://www.kcmf.vsu. ru/resources/t_16_1_2014_010.pdf (in Russ.)

23. Tretyakov Yu. D., et. al. Neorganicheskaja himija: Himija elementov: Uchebnik dlja stud. him. fak. un-tov [Inorganic Chemistry: Chemistry of Elements: A Textbook for students. chem. fact. un-tov. Moscow, Academic Book Publ., 2007, 1216 p.

24. Mittova I. Ya., Vasil'eva V. V., Terehov V. A. Izvestija AN SSSR. Serija Neorganicheskie materialy [News of the Academy of Sciences of the USSR. Series Inorganic Materials], 1988, vol. 24, no. 12, pp. 1941-1944. (in Russ.).

25. Mittova I. Ya., Sviridova V. V., Semenov V. N. Izvestija AN SSSR. Serija Neorganicheskie Materialy [News of the Academy of Sciences of the USSR. Series Inorganic Materials], 1989, vol. 25, no. 6, pp. 908-911. (in Russ.)

26. Mittova I. Ya., Sviridova V. V., Fetisova S. V. Izvestija AN SSSR. Serija Neorganicheskie Materialy [News of the Academy of Sciences of the USSR. Series Inorganic Materials], 1992, vol. 28, no. 9, pp. 1829-1832. (in Russ.)

27. Mittova I. Ya., Sviridova V. V., Fetisova S. V. Izvestija AN SSSR. Serija Neorganicheskie Materialy [News of the Academy of Sciences of the USSR. Series Inorganic Materials], 1990, vol. 26, no. 10, pp. 2013-2016. (in Russ.)

28. Mittova I. Ya., Sviridova V. V., Fetisova S. V. Izvestija AN SSSR. Serija Neorganicheskie Materialy [News of the Academy of Sciences of the USSR. Series Inorganic Materials], 1991, vol. 27, no. 12, pp. 2488-2490. (in Russ.)

29. Mittova I. Ya., Pshestanchik V. R., Malyshev O. M. Izvestija AN SSSR. Serija Neorganicheskie Materialy [News 
of the Academy of Sciences of the USSR. Series Inorganic Materials], 1992, vol. 28, no. 5, pp. 2041-2044. (in Russ.)

30. Mittova I. Ya., Sviridova V. V., Koljukaeva I. A. Izvestija AN SSSR. Serija Neorganicheskie Materialy [News of the Academy of Sciences of the USSR. Series Inorganic Materials], 1989, vol. 25, no. 12, pp. 1954-1958. (in Russ.)

31. Mittova I. Ya., Pshestanchik V. R., Soshnikov V. V. Doklady chemistry [Reports of the Russian Academy of Sciences], 1997, vol. 354, no. 3, pp. 343-345. (in Russ.)

32. Mittova I. Ya., Soshnikov V. V., Kashkarov V. M., Pshestanchik V. R. Neorganicheskie Materialy [Inorganic Materials], 1999, vol. 35, no. 1, pp. 13-16. (in Russ.)

33. Mittova I. Ya., Borzakova G. V., Terehov V. A. Izvestija AN SSSR. Serija Neorganicheskie Materialy [News of the Academy of Sciences of the USSR. Series Inorganic Materials], 1991, vol. 27, no. 10, pp. 2047-2051. (in Russ.)

34. Rode T. V. Kislorodnye soedinenija hroma $i$ hromovye katalizatory [Oxygen Compounds of Chromium and Chromium Catalysts]. Moscow, USSR AS Publ., 1962, pp. 20. (in Russ.)

35. Lobanov N. N., Izotov A. D., Pashkova O. N. Inorganic Materials, 2015, vol. 51, no. 12, pp. 1185-1189. DOI: 10.1134/S0020168515120067

36. Yarzhemsky V. G., Murashov S. V., Izotov A. D. Doklady Physics, 2015, vol. 60, no. 11, pp. 491-494. DOI: 10.1134/S1028335815110087

37. Yarzhemsky V. G., Murashov S. V., Izotov A. D. Inorganic Materials, 2017, vol. 53, no. 11, pp. 1131-1135. DOI: $10.1134 / \mathrm{S} 0020168517110176$

38. Guimond S., Sturm J. M., Gцbke D., Romanyshyn Y., Naschitzki M., Kuhlenbeck H., Freund H.-J. Journal of Physical Chemistry C, 2008, vol. 112, no. 31, pp. 1183511846. DOI: $10.1021 /$ jp8011156.

39. Atuchin V. V., Kochubey V. A., Pokrovsky L. D., Kruchinin V. N., Ramana C. V., Optics and Spectroscopy, 2014, vol. 117, no. 3, pp 423-427. DOI: 10.1134/ S0030400X14090033

40. Shahid M., Shakir I., Yang S.-J., Kang D. J. Materials Chemistry and Physics, 2010, vol. 124, no. 1, pp. 619-622. DOI: 10.1016/j.matchemphys.2010.07.023.

41. Dhaz-Guerra C., Piqueras J. Crystal Growth \& Design, 2008, vol. 8, no. 3, pp. 1031-1034. DOI: 10.1021/ cg070612w.

42. Zaharova G. S. Intercalates of Vanadium Oxides and Nanotubules Based on Them: Synthesis, Structure, Properties. Diss. doct. chem. sci. Ekaterinburg, 2007, 277 p. (in Russ.)

43. Livage J. Chemistry of Materials, 1991, no. 3, pp. 578-593. DOI: 10.1021/cm00016a006

44. Grigorieva A. V., Tarasov, A. B., Goodilin E. A., Volkov V. V., Tretyakov Yu. D. Glass Physics and Chemistry, 2007, vol. 33, no. 3, pp. 232-236. DOI: 10.1134/ S1087659607030078
45. Stefanovich G. B., Pergament A. L., Kazakova E. L. Technical Physics Letters, 2000, vol. 26, no. 11, pp. 478480. DOI: $10.1134 / 1.1262883$

46. Berezina O. Ya., Velichko A. A., Lugovskaya L. A., Pergament A. L., Stefanovich G. B. Inorganic Materials, 2007, vol. 43, no. 5, pp. 505-511. DOI: 10.1134/ S0020168507050123

47. Krylov O. V. Geterogennyj kataliz [Heterogeneous Catalysis]. Moscow, Akademkniga Publ., 2004, 679 p. (in Russ.)

48. Glushko V.P. Termodinamicheskie svojstva individual'nyh veshhestv. Spravochnoe izdanie [Thermodynamic Properties of Individual Substances]. Moscow, Nauka Publ., 1985. (in Russ.)

49. Kazenas E. K. Termodinamika isparenija oksidov [Thermodynamics of Evaporation of Oxides]. Moscow, LKI Publ., 2007, 474 p. (in Russ.)

50. Mittova I. Ya., Sviridova V. V., Semenov V. N., Kuznetsova I. V. Izvestija AN SSSR. Serija Neorganicheskie Materialy [News of the Academy of Sciences of the USSR. Series Inorganic Materials], 1991, vol. 27, no. 5, pp. 897900. (in Russ.)

51. Mittova I. Ya., Sviridova V. V., Semenov V. N. Izvestija AN SSSR. Serija Neorganicheskie Materialy [News of the Academy of Sciences of the USSR. Series Inorganic Materials], 1991, vol. 27, no. 12, pp. 2491-2494. (in Russ.)

52. Tomina E. V., Sukhochev A. S., Meshcheryakova E. K., Mittova I. Ya. Inorganic Materials, 2007, vol. 43, no. 5, pp. 520-525. DOI: 10.1134/S0020168507050159

53. Mittova I. Ya., Tomina E. V., Sukhochev A. S., Vasyukevich A. O. Inorganic Materials, 2003, vol. 39, no. 12, c. 1284-1287. DOI: 10.1023/B:INMA.0000008914. 56903.be

54. Tomina E. V., Mittova I. Ya., Sukhochev A. S., Sladkopevtsev B. V. Glass Physics and Chemistry, 2010, vol. 36, no. 2, pp 238-246. DOI: 10.1134/S1087659610020136

55. Sukhochev A. S., Tomina E. V., Mittova I. Ya. Glass Physics and Chemistry, 2008, vol. 34, no. 6, pp. 724-741. DOI: $10.1134 / \mathrm{S} 1087659608060102$

56. Tomina E. V., Sukhochev A. S., Meshcheryakova E. K., Mittova I. Ya. Poverhnost'. Rentgenovskie, sinhrotronnye i nejtronnye issledovanija [Journal of Surface Investigation. X-ray, Synchrotron and Neutron Techniques], 2008, no. 11, pp. 88-92. (in Russ.)

57. Mittova I. Ya., Tomina E. V., Khorohordina A. O., Sukhochev A. S. Poverhnost'. Rentgenovskie, sinhrotronnye i nejtronnye issledovanija [Journal of Surface Investigation. X-ray, Synchrotron and Neutron Techniques], 2004, no. 9, pp. 69-72. (in Russ.)

58. Mittova I. Ya., Tomina E. V., Sukhochev A. S., Prokin A. N., Vasyukevich A. O. Russian Microelectronics, 2002, vol. 31, no. 2, pp. 84-87. DOI: 10.1023/ A:1014385224423

59. Mittova I. Ya. Neorganicheskie Materialy [Inorganic Materials], 1992, vol. 28, no. 5, pp. 917-927. (in Russ.) 
60. Mittova I. Ya., Pshestanchik V. R. Doklady Akademii Nauk SSSR, 1991, vol. 318, no. 1, pp. 139-143. (in Russ.)

61. Lapenko A. A., Lisitsyn S. V., Tomina E. V., Valyukhov D. P., Mittova I. Ya. Inorganic Materials, 2008, vol. 44, no. 11, pp. 1163-1168. DOI: 10.1134/ S0020168508110022

62. Wells A. F. Structural Inorganic Chemistry: Vol. 3. Oxford, Oxford University Press, 1984, 1382 p.

63. Shvets V. A., Rykhlitskii S. V., Mittova I. Ya., Tomina E. V. Technical Physics, 2013, vol. 58, no. 11, pp. 1638-1645. DOI: 10.1134/S1063784213110248

64. Mittova I. Ya., Shvets V. A., Tomina E. V., Sladkopevtsev B. V., Tret'yakov N. N., Lapenko A. A. Inorganic Materials, 2013, vol. 49, no. 2, pp. 179-184. DOI: 10.1134/ S0020168513020143
65. Mittova I. Ya., Shvets V. A., Tomina E. V., Samsonov A. A., Sladkopevtsev B. V., Tret'yakov N. N. Inorganic Materials, 2013, vol. 49, no. 10, pp. 963-970. DOI: $10.1134 / \mathrm{S} 0020168513100075$

66. Tutov E. A., Vinichenko D. A., Tutov E. E., AlKhafaji H. I., Rumyantseva N. A., Zlomanov V. P. Condensed Matter and Interphase, 2011, vol. 13, no. 3, pp. 358-362. Available at: http://www.kcmf.vsu.ru/resources/t_13_3_2011_018.pdf (in Russ.)

67. Sladkopevtsev B. V., Tomina E. V., Mittova I. Ya., Dontsov A. I., Pelipenko D. I. Journal of Surface Investigation. X-ray, Synchrotron and Neutron Techniques, 2016, vol. 10, no. 2, pp. 335-340. DOI: 10.1134/ S102745101602018X
Томина Елена Викторовна - д. х. Н., доцент, доцент кафедры материаловедения и индустрии наносистем, Воронежский государственный университет; тел.: +7(473) 2208356; e-mail: tomina-ev@yandex.ru

Миттова Ирина Яковлевна - д. х. н., професcop, профессор кафедры материаловедения и индустрии наносистем, Воронежский государственный университет; тел.: +7(473) 2208356; e-mail: imittova@mail.ru

Сладкопевцев Борис Владимирович - к. х. н., доцент кафедры материаловедения и индустрии наносистем, Воронежский государственный университет; тел.: +7(905) 6505334; e-mail: dp-kmins@ yandex.ru

Кострюков Виктор Федорович - д. х. н., доцент, доцент кафедры материаловедения и индустрии наносистем, Воронежский государственный университет; тел.: +7(473) 2208356; e-mail: vc@ chem.vsu.ru

Самсонов Алексей Алексеевич - к. х. н., ведущий инженер кафедры материаловедения и индустрии наносистем, Воронежский государственный университет; тел.: +7(903) 6536485; e-mail: samsonjr@mail.ru

Третьяков Никита Николаевич - выпускник кафедры материаловедения и индустрии наносистем, Воронежский государственный университет; тел.: +7(952) 5519531; e-mail: nikos31@mail.ru
Elena V. Tomina - Dr. Sci. (Chem.), Associate Professor, Associate Professor of the Department of Materials Science and Industry of Nanosystems, Voronezh State University; tel.: +7(473) 2208356, e-mail: tomina-e-v@yandex.ru

Irina Y. Mittova - Dr. Sci. (Chem.), Full Professor, Professor of the Department of Materials Science and Industry of Nanosystems, Voronezh State University; tel.: +7(473) 2208356, e-mail: imittova@mail.ru

Boris V. Sladkopevtsev - Cand. Sci. (Chem.), Associate Professor of the Department of Materials Science and Industry of Nanosystems, Voronezh State University; tel.: +7(905) 6505334, e-mail: dp-kmins@ yandex.ru

Victor F. Kostryukov - Dr. Sci. (Chem.), Associate Professor, Associate Professor of the Department of Materials Science and Industry of Nanosystems, Voronezh State University; tel.: +7(473) 2208356, e-mail: vc@chem.vsu.ru

Alexey V. Samsonov - Cand. Sci. (Chem.), Lead Engineer of the Department of Materials Science and Industry of Nanosystems, Voronezh State University; tel.: +7(903) 6536485, e-mail: samsonjr@mail.ru

Nikita N. Tretyakov - graduate of the Department of Materials Science and Industry of Nanosystems, Voronezh State University; tel.: +7(952) 5519531, email: nikos31@mail.ru 